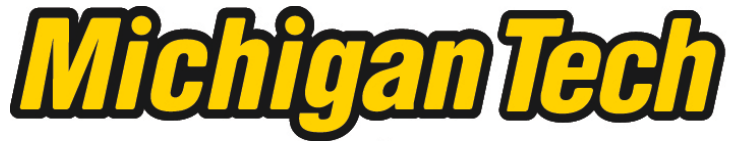 \\ Michigan Technological University Create the Future Digital Commons @ Michigan Tech
}

Effects of fixed night shift work on $\mathbf{2 4}$ hour blood pressure regulation, state anxiety levels and total sleep time

Jennifer L. Witting

Michigan Technological University

Follow this and additional works at: https://digitalcommons.mtu.edu/etds

Part of the Biology Commons

Copyright 2011 Jennifer L. Witting

\section{Recommended Citation}

Witting, Jennifer L., "Effects of fixed night shift work on 24 hour blood pressure regulation, state anxiety levels and total sleep time", Master's Thesis, Michigan Technological University, 2011.

https://doi.org/10.37099/mtu.dc.etds/188

Follow this and additional works at: https://digitalcommons.mtu.edu/etds

Part of the Biology Commons 


\title{
THE EFFECTS OF FIXED NIGHT SHIFT WORK ON 24 HOUR BLOOD PRESSURE REGULATION, STATE ANXIETY LEVELS AND TOTAL SLEEP TIME
}

Jennifer L. Witting

\begin{abstract}
A THESIS
Submitted in partial fulfillment of the requirements for the degree of MASTER OF SCIENCE

(Biological Sciences)
\end{abstract}

MICHIGAN TECHNOLOGICAL UNIVERSITY

2011

(C) 2011 Jennifer L. Witting 
This thesis, "The Effects of Fixed Night Shift Work on 24 Hour Blood Pressure Regulation, State Anxiety Levels and Total Sleep Time," is hereby approved in partial fulfillment of the requirements for the degree of MASTER OF SCIENCE IN BIOLOGICAL SCIENCES.

Department of Biological Sciences

Signatures:

Thesis Co-Advisor

Jason R. Carter, PhD

Thesis Co-Advisor

John J. Durocher, PhD

Department Chair

K. Michael Gibson, PhD

Date 


\section{Table of Contents}

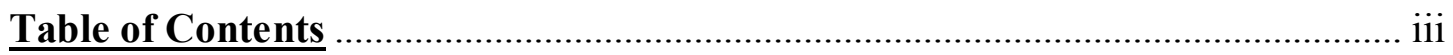

List of Figures

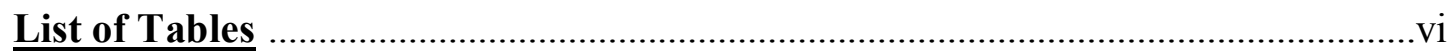

Acknowledgments

List of Abbreviations

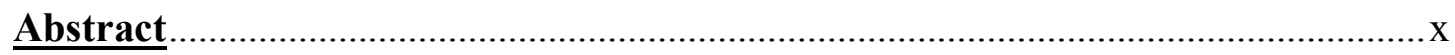

Effects of Night Shift Work on 24 Hour Blood Pressure Regulation, State Anxiety Levels and Total Sleep Time.

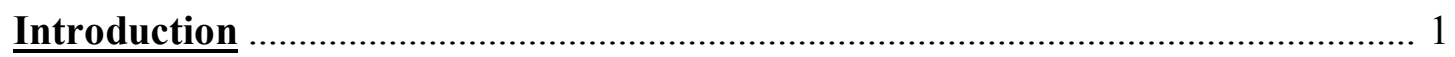

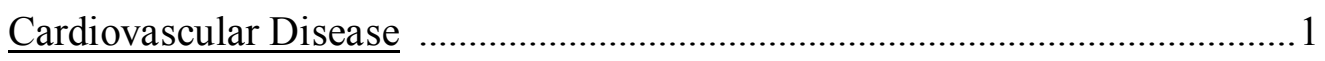

Blood Pressure …............................................................................................

24 Hour Blood Pressure Profile ........................................................................ 5

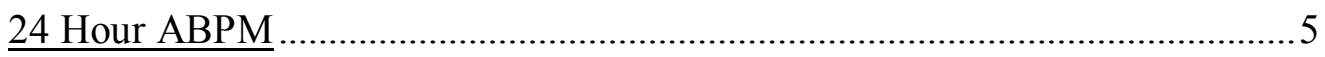

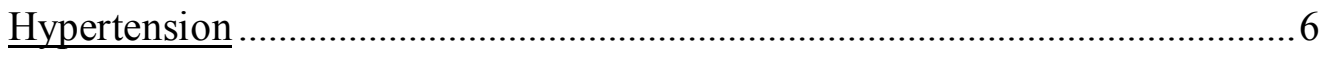

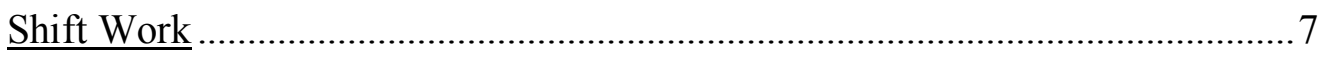

Sleep Duration in Shift Workers.................................................................. 9

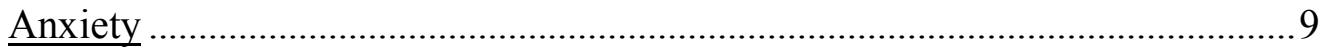

STAI 


\section{Methods}

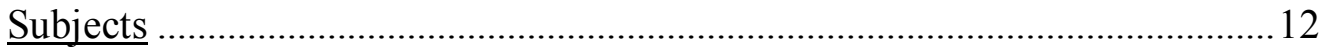

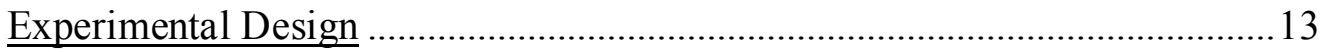

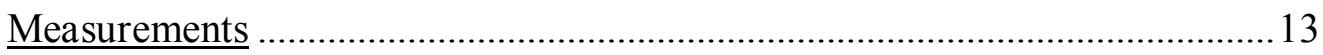

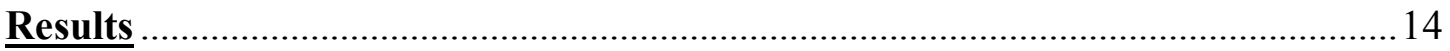

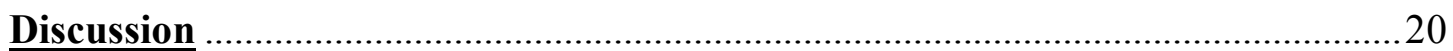

Clinical Implications/Areas of Future Research ...............................................25

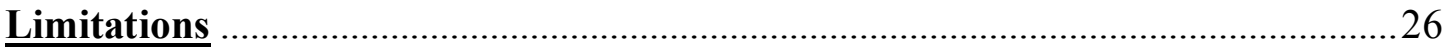

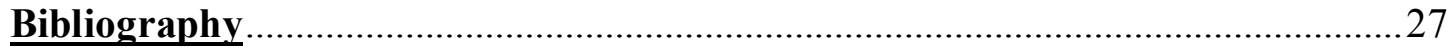

Appendices: Raw Data and Statistics:

Appendix A: Raw 24 Hour Blood Pressure Data ...............................................33

Appendix B: Original Repeated Measures ANOVA Statistics...........................33

Appendix B-1: Updated Repeated Measures ANOVA Statistics.......................37

Appendix B-2: Pearson Correlation Statistics ..............................................43

Appendix B-3: Post Hoc Paired T-Test Statistics...........................................44

Appendix C: Subject Information Questionnaire ......................................48

Appendix D: STAI Questionnaire, Form Y-1 ............................................49

Appendix D-1: STAI Questionnaire, Form Y-2 …......................................50

Appendix D-2: STAI Approval Letter ........................................................51

Appendix E: Caffeine Intake Report Sheet ..................................................52 
Appendix F: Self Report Sleep Diary.

Appendix G: Subject Recruitment Flyer ...........................................................54 


\section{List of Figures}

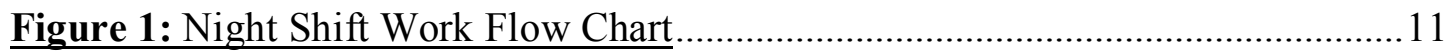

Figure 2: Combined Sleep Time for Night and Day Shift Workers ............................15

Figure 3: Total Sleep Time, Work Day versus Off Day............................................ 15

Figure 4: 24 Hour SAP, DAP, MAP and HR, Work Day versus Off Day................... 16

Figure 5: Raw State Anxiety Scores, Work Day versus Off Day ..............................18

Figure 6: $\Delta$ Total Sleep Time and $\Delta$ State Anxiety Scores, Work Day versus Off Day .18

Figure 7: $\Delta$ Total Sleep Minutes and $\Delta$ BP, Work Day versus Off Day ......................19

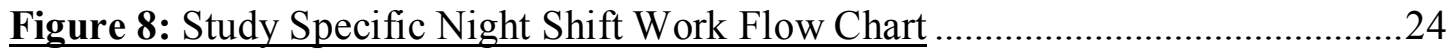




\section{List of Tables}

Table 1.1: Baseline Subject Characteristics................................................................. 12

Table 1.2: 24 hour blood pressure and heart rate, off day versus work day.................17 


\section{Acknowledgements}

This thesis and degree has been a long but rewarding portion of the past 5 years of my life. This experience was made possible by many faculty and staff members and fellow students. I would like to thank my co-advisors, Dr. Jason Carter and Dr. John Durocher, for all the time and expertise spent with me during this project. I would also like to thank my committee members, especially Dr. Thomas Drummer, for all of his support and patience as I attempted to learn and enjoy the field of statistics. I would like to extend a big thanks to all of my fellow graduate students for both your help in the lab and for giving me a shoulder to lean on when times got tough. Lastly, I would like to mention the overwhelming amount of support and love that my family has given me during this entire experience from start to finish. Thanks for never giving up on me, I love you all. 


\section{List of Abbreviations}

$\begin{array}{ll}\text { ABPM } & \text { Ambulatory blood pressure monitor } \\ \text { BMI } & \text { Body mass index } \\ \text { bPm } & \text { Beats per minute } \\ \text { BP } & \text { Blood pressure } \\ \text { CVD } & \text { Cardiovascular disease } \\ \text { DAP } & \text { Diastolic arterial pressure } \\ \text { HR } & \text { Heart rate } \\ \text { HTN } & \text { Hypertension } \\ \text { JNC7 } & 7^{\text {th }} \text { Joint National Committee on prevention, detection, evaluation and } \\ & \text { treatment of high blood pressure } \\ \text { MAP } & \text { Mean arterial pressure } \\ \text { mmHg } & \text { Millimeters of Mercury } \\ \text { SAP } & \text { Systolic arterial pressure }\end{array}$




\begin{abstract}
Nearly 22 million Americans operate as shift workers, and shift work has been linked to the development of cardiovascular disease (CVD). This study is aimed at identifying pivotal risk factors of CVD by assessing 24 hour ambulatory blood pressure, state anxiety levels and sleep patterns in 12 hour fixed shift workers. We hypothesized that night shift work would negatively affect blood pressure regulation, anxiety levels and sleep patterns. A total of 28 subjects (ages 22-60) were divided into two groups: 12 hour fixed night shift workers $(n=15)$ and 12 hour fixed day shift workers $(n=13) .24$ hour ambulatory blood pressure measurements (Space Labs 90207) were taken twice: once during a regular work day and once on a non-work day. State anxiety levels were assessed on both test days using the Speilberger's State Trait Anxiety Inventory. Total sleep time (TST) was determined using self recorded sleep diary. Night shift workers demonstrated increases in 24 hour systolic ( $122 \pm 2$ to $126 \pm 2 \mathrm{mmHg}, \mathrm{P}=0.012)$; diastolic ( $75 \pm 1$ to 79 $\pm 2 \mathrm{mmHg}, \mathrm{P}=0.001)$; and mean arterial pressures $(90 \pm 2$ to $94 \pm 2 \mathrm{mmHg}, \mathrm{P}<0.001)$ during work days compared to off days. In contrast, 24 hour blood pressures were similar during work and off days in day shift workers. Night shift workers reported less TST on work days versus off days ( $345 \pm 16$ vs. $552 \pm 30 \mathrm{~min} ; \mathrm{P}<0.001)$, whereas day shift workers reported similar TST during work and off days (475 \pm 16 minutes to $437 \pm 20$ minutes; $\mathrm{P}=0.231$ ). State anxiety scores did not differ between the groups or testing days (time* group interaction $\mathrm{P}=0.248$ ), suggesting increased 24 hour blood pressure during night shift work is related to decreased TST, not short term anxiety. Our findings suggest that fixed night shift work causes disruption of the normal sleep-wake cycle negatively affecting acute blood pressure regulation, which may increase the long-term risk for CVD.
\end{abstract}




\section{Introduction}

\section{Cardiovascular Disease}

Cardiovascular disease (CVD) is an epidemic in the United States, and the risk for CVD is directly related to the 24 hour regulation of arterial blood pressure (BP) ( Harrington 1978; Rochella et al. 2003; Lloyd-Jones et al. 2010). CVD has been the number one cause of death in the United States since 1900, with the exception of the 1918 flu epidemic (Lloyd-Jones et al. 2010). Approximately 81 million Americans currently have one or more types of CVD, with hypertension (HTN) being the most prevalent (Lloyd-Jones et al. 2010). Despite decreases in CVD related death over the last ten years, the incidence of CVD is still on the rise.

There are many known contributing risk factors of CVD including family genetics and lifestyle characteristics such as diet, physical inactivity and smoking (Appel et al 1997; Rochella et al. 2003; Lloyd-Jones et al. 2010). The seventh report of the Joint National Commission on the prevention, evaluation and treatment of high BP (JNC 7) reports that a healthy lifestyle is crucial for both a reduction and a prevention of hypertension (Appel et al. 1997; Rochella et al. 2003). A weight loss of as little as ten pounds along with the addition of 30 minutes of physical activity, on most days of the week, can significantly reduce BP levels (Appel et al. 1997; Rochella et al. 2003; LloydJones et al. 2010). Diet is also a major factor in the development of HTN, and both the JNC 7 and reports from the New England Journal of Medicine back a diet that is rich in fruits, vegetables, omega 3 fatty acids and low fat dairy products to help reduce the incidence of high blood pressure (Appel et al. 1997; Rochella et al. 2003). Reducing intake of dietary cholesterol, saturated fats, and total fat will typically help to reduce BP levels. Lifestyle modification, including the cessation of smoking and reduction of alcohol intake, may be the only change some individuals need to positively influence their cardiovascular health (Appel et al. 1997; Rochella et al. 2003; Lloyd-Jones et al. 2010). However, other individuals may have work related factors that contribute to CVD. 
Job type and specificity, particularly shift work, have been considered a potential occupational risk factor for long term development of CVD. Studies have reported that night shift workers have up to a 40 percent increased risk of developing CVD when compared to day shift workers, demonstrating the significance of this work-health relationship (Boggild et al. 1999; Knuttson 2003). Furthermore, the landmark Framingham heart study predicted that $90 \%$ of all people over the age of 55 will develop HTN, making research on BP regulation extremely important (Dawber et al. 1966; Rochella et al. 2003). Harrington (1978) was one of the earliest to evaluate shift work and its effects on the human body, despite shift work dating back to about 1750. The report of the Health of Munitions Workers Committee (1918) stated, that "excessive long hours of work, particularly night shift work, when continued over time would produce fatigue, irritation and sickness, including the development of CVD." The studies were used to determine proper work hours to obtain maximum output per shift without causing any symptomatic response by the worker. It was identified that a reduction of shift length time from 12 to 7 hours increased output and overall well being by $6.5 \%$ (Health of Munitions Worker Committee 1918). Similar findings on output and hours were calculated during the Second World War (Harrington 1978). The popularity of shift work is growing not only in our own country, but also many others, giving rise to concern of its health effects on the working population. Harrington (1978) and others note that night shift work disrupts the normal pattern of circadian rhythms (Aschoff 1965; Bryden and Holdstock 1973; Sack et al. 2007).

It remains unknown how shift work affects state anxiety levels, total sleep time, and 24 hour BP regulation in 12 hour fixed night shift workers. This thesis examines these relations during 12 hour fixed day and night shifts, rather than 8 hour shifts or rotating shifts, which is what previous studies have primarily examined (Chau et al. 1989; Adams 1998; Ohira et al 2000; Lo et al. 2008; Su et al. 2008). The National Institute for Occupational Safety and Health (NIOSH), with the help of the organization CIRCADIAN $^{\odot}$, reports on annual work performance and safety. According to their 2004 survey, $43 \%$ of non-regulated industries, including healthcare, use 12 hour shift 
scheduling, making research in this area exceedingly important (Dawson et al 2004). Furthermore, in 2010 the Center for Disease Control estimated the cost of high BP medications and missed days of work in the United States to be 76.6 billion dollars (CDC 2010). The JNC 7 also reports that $30 \%$ of all individuals with HTN are unaware of its presence making the undiagnosed and untreated a dangerous combination (Rochella et al. 2003).

\section{Blood Pressure}

The following equation is used to calculate mean arterial pressure (MAP): $\mathrm{MAP}=$ CO X TPR. Cardiac output (CO) is the product of both stroke volume, which relies on the contractility of the heart tissue and the volume of blood in the heart, and heart rate. Total peripheral resistance (TPR) is the total amount of resistance in the peripheral vasculature contained in the systemic system. Increases or decreases of either CO or TPR can alter BP levels (Stead and Kunkel 1939; Fries 1960).

Blood pressure in the human body is regulated multiple ways and different regulation systems adjust BP over a multitude of time frames (Guyton 1991, 1992; Rowell 1993). The autonomic nervous system, which includes the baroreflex mechanism, is the most sensitive and rapidly acting blood pressure regulation system (Guyton 1991, 1992). The baroreflex is a negative feedback mechanism relying on stretch receptors located in the aortic arch and carotid sinuses that activate whenever there is an increase or decrease in arterial BP (Freis 1960; Guyton 1991, 1992; Rowell 1993). Most autonomic effectors have a degree of resting activity, and a change in a particular direction will increase or decrease the effectors activity to produce a desired influence on BP control (Korner 1971). Increases in BP stretch baroreceptors within the aortic arch and carotid sinuses stimulate action potentials in the afferent sensory nerve fibers and propagate them to the medulla oblongata (Stead and Kunkel 1939; Fries 1960; Guyton 1991; Rowell 1993). The increase in afferent activity to the medulla triggers a reduction in efferent sympathetic outflow, which induces vasodilation to reduce total peripheral resistance (TPR), and allows BP to decrease back towards normal levels (Guyton 1991, 1992). 
Conversely, when there is a decrease in BP, afferent signals to the medulla are reduced, increasing BP back to normal levels via increased sympathetic activation (Freis 1960; Guyton 1991; Rowell 1993). The baroreceptors are extremely sensitive to BP changes; however they are not the sole regulators of arterial BP and must be accompanied by other BP regulating systems (Guyton 1991).

There are two other fast acting BP regulation systems in the CNS, the ischemic pressure system and the chemoreceptor system (Stead and Kunkel 1939; Freis 1960; Guyton 1991, 1992; Rowell 1993). Limited blood flow to the brain stimulates the ischemic control system via the medulla and the sympathetic nervous system while decreased levels of oxygen and increased levels of carbon dioxide in the blood are triggers for chemoreceptors (Korner 1971; Guyton 1991). The chemoreceptor system is particularly important for BP control during exercise due to increased amount of oxygen used and carbon dioxide produced by muscle (up to 20 times the resting amount) during exercise (Freis 1960; Guyton 1991, 1992;).

Intermediate pressure control systems start to take effect shortly after the fast acting systems (Stead and Kunkel 1939; Guyton 1991, 1992; Rowell 1993). The reninangiotensin system, the stress relaxation system, the aldosterone system, and the capillary fluid shift mechanism control BP by fluid regulation (Stead and Kunkel 1939; Guyton 1991, 1992; Navar 2010). It is believed that these systems are the most effective long term BP regulators (Stead and Kunkel 1939; Guyton et al 1972; Guyton 1991; Navar 2010). These systems may be stimulated for hours after BP changes take place (Freis 1960; Guyton 1991).

The kidneys regulate BP by controlling blood volume via water and salt retention. As BP increases or decreases, the renin-angiotensin system can induce vasoconstriction, vasodilation or alter blood volume to help keep BP in a normal range. Key hormones released include angiotensin II, adrenaline and noradrenaline, all of which are vasoconstrictors. Vasodilator hormones such as nitric oxide, epinephrine and atrial natriuretic peptide can have the opposite response, and decrease BP. BP regulation is 
achieved by all of the above physiological mechanisms in an integrated manner (Stead and Kunkel 1939; Guyton et al 1972; Guyton 1991; Navar 2010).

\section{Hour Blood Pressure Profile}

24 hour BP profiling with the use of ambulatory blood pressure monitoring (ABPM) was first introduced 40 years ago. It has become increasingly popular over the past 20 years, and is now recognized as a gold standard for blood pressure monitoring (Pickering 2006a). 24 hour ABPM offers the ability to monitor subjects throughout their daily routines and is useful in identifying patterns of dynamic BP changes during different activities (Peiper 2003; Pickering 2006a; Su et al. 2008). It is also considered to be a useful tool for predicting the development of HTN and CVD. This method has been used often to assess 24 hour BP profiles in the shift work population, most notably night shift workers (Adams 1998; Lo et al. 2008; Su et al. 2008). Increased systolic and diastolic pressures, as well as HR, have been reportedly linked to nightshift work in both physicians and nursing staff (Adams 1998; Lo et al. 2008). Night shift workers are reported to have a greater BP during a work day when compared to a non-work day (Adams 1998; Lo et al. 2008). Increases in systolic BP, diastolic BP, and HR have been reported during 12 hour night shifts ( $\mathrm{Su}$ et al. 2008). However, previous shift work research has specifically focused on the potential for sleep loss and increased anxiety to directly influence 24 hour BP.

BP increases as small as $5 \mathrm{mmHg}$ for systolic diastolic BP can be clinically relevant, especially if re-occurring over extended periods of time by increasing the risk of adverse cardiovascular events (Rochella et al. 2003). Patients who have 24 hour BPs above $135 / 85 \mathrm{mmHg}$ are almost twice as likely to suffer a cardiovascular event compared to those below 130/85 mmHg (Pickering 2002; Rochella et al. 2003).

\section{Hour ABPM}

$\mathrm{BP}$ is often measured and monitored during visits to a primary care physician, and may consist of only one reading taken and recorded in the seated position. Office BP 
readings can be inaccurate due to the fact that the patient is in the presence of the doctor. This phenomenon can cause increased BP and is referred to as "white coat HTN." White coat HTN has been researched and it has been determined that prescription medication rates are increased secondary to this diagnosis (O’Brien 2008). As a result, physicians are more frequently prescribing a blood pressure monitoring device, and the two options are self blood pressure monitoring or 24 hour ABPM. The 24 hour ABPM option is preferred due to its reliability and ability to record nocturnal BP measurements unlike self blood pressure monitoring (O’Brien 2008; Omboni 1997; Staessen 1999). The physician can set the monitor to take readings multiple times per hour and it is pre-set, minimizing patient error (O'Brien 1991, 2008). The particular model used in this thesis, the SpaceLabs ABPM model 90207, has been deemed suitable for the use of 24 hour ABPM by the British Hypertension Society (O’Brien 1991).

24 hour ABPM is classified differently because BP measurements are taken over a longer duration of time, including both ambulatory and sleep periods. Normal day time ABPM measurements are typically $\leq 130 / 85 \mathrm{mmHg}$, while night time measurements drop down to approximately $110 / 70 \mathrm{mmHg}$ (O’Brien 1991, 2008). This night time drop is believed to be due to a decrease in HR, a decrease in physical activity, and the postural change that takes place while lying down (O’Brien 1991, 2008; Rochella et al. 2003).

\section{Hypertension}

HTN is one of the most common types of CVD (Rochella et al. 2003). HTN is defined as BP levels that are high enough to cause damage to the heart, blood vessels, and surrounding tissues (Appel et al. 1997; Rochella et al. 2003). Increased BP overstretches the vascular walls causing injury and forcing the heart to work harder in order to compensate (Stead and Kunkel 1939; Freis 1960; Lily 2007).

Normal BP is considered to be readings below $120 \mathrm{mmHg}$ for systolic pressure and less than $80 \mathrm{mmHg}$ for diastolic pressure (Appel et al. 1997; Rochella et al. 2003; Lloyd-Jones et al. 2010). Systolic pressure is generated and recorded during the ejection 
of blood from the heart, while diastolic pressure is the pressure remaining in the blood vessels when the heart relaxes between beats (Freis 1960; Rowell 1993). High BP typically begins with pre-HTN, systolic pressure in the range of 120-139 $\mathrm{mmHg}$ and/or diastolic pressure in the range of 80-89 mmHg (Appel et al. 1997; Rochella et al. 2003). HTN is defined as a systolic reading ofl $40 \mathrm{mmHg}$ systolic an $\mathrm{d} /$ or a diastolic reading of $\geq 90 \mathrm{mmHg}$ (stage $1 \mathrm{HTN}$ ). 24 hour ambulatory BP over the level of 130/85 is considered to be HTN (O’Brien 1991, 2008).

There are two forms of HTN, primary HTN and secondary HTN. Primary HTN is more common; about $95 \%$ of all diagnosed cases. It is thought that primary HTN is the combination of multiple BP regulation problems and environmental stressors, which makes it more difficult to treat (Appel et al. 1997; Rochella et al. 2003). Secondary HTN develops after another medical problem has arisen in the body, thus an effective treatment is more likely. If BP continues to rise, the severity and category of HTN also increases. Stage $2 \mathrm{HTN}$ is defined as $\mathrm{BP} \geq 160 / 100 \mathrm{mmHg}$ and stage $3 \mathrm{HTN}$ is considered severe (systolic $\geq 180 \mathrm{mmHg}$ and diastolic $\geq 110 \mathrm{mmHg}$ ). Individuals experiencing HTN can develop headaches, epistaxsis and dizziness, but as mentioned previously, sometimes signs and symptoms of HTN are not present (Rochella et al. 2003; Guyton and Hall 2006; Lloyd-Jones et al. 2010).

\section{Shift Work}

Over the last two decades, shift work has become much more prevalent and it is now a staple in the United States workforce and many other countries (Dawson et al 2004; Pickering 2006a; Srivastava 2010). Shift work is identified as work hours that extend beyond the normal 8 -hour work day of 8 a.m. to 5 p.m. It is common for these shifts to be 12 hours or longer, and they are often worked in succession to one another (Akerstedt 1990; Kawachi et al. 1995; Knutsson 2003). There are different types of shift work classified as non-rotating shift work, rotating shift work and fixed day or night shift work (Akerstedt 1990; Kawachi et al. 1995; Srivastava 2010). The Journal of Family Practice reports that 22 million Americans participate in some form of shift work 
(Culpepper 2010). About 3.8 million workers have fixed night schedules, approximately 3.3 million work rotating night shifts, and the remaining work either fixed days or rotational day work (Culpepper 2010).

Nearly all body functions are rhythmic and cyclic; working extended periods of night shift work or rotating shift work can alter the bodies' normal patterns (Aschoff 1965; Mills 1966; Bryden 1973; Harrington 1978, 2001; Drake et al 2010; Schwartz 2010). These alterations can impact weight, physical activity, social interaction and sleep. The human sleep-wake cycle functions under the command of two systems: 1) the circadian system which promotes wakefulness and 2) the homeostatic system which promotes sleep (Aschoff 1965; Mills 1966; Culpepper 2010; Drake et al 2010). When these internal regulatory mechanisms get out of synchronization, the body cannot maintain its normal sleep/wake cycles. This disruption essentially confuses the body of when it is supposed to rest and be awake, causing decreases in total sleep time and/or less effective sleep (Akerstedt 1984; Drake 2010; Nagai 2010; Schwartz 2010). Due to the nature of shift work, and the altering of these bodily functions, individuals participating in shift work are at risk for health problems such as sleep disorders, cardiovascular disease, digestive problems and psychological disorders (Harrington 1978, 2001, Knutsson 2003; Sack et al. 2007; Culpepper 2010).

The demands of shift work include elevated mental stress, decreased TST and altered regulatory functions, all of which have the potential to increase BP and ultimately increasing the risk of CVD (Harrington 1978, 2001; Akerstedt 2001; Knutsson 2003; Lo 2008; Srivastava 2010). Studies done on the general population reported that 32.1 percent of night shift workers and 26.1 percent of rotating-shift workers met excessive sleepiness or insomnia criteria, as determined by the Epworth Sleepiness Scale, while only 18 percent of day workers met the same criteria (Drake et al. 2010). Sleep related issues can lead to other problems such as fatigue, and the recognition of fatigue is crucial because it is often an indicator of an underlying sleep disorder. Approximately $30 \%$ of shift workers suffer with sleep disorders (Drake et al. 2010). Because shift work tends to negatively influence sleep and induce fatigue, anxiety levels may also increase. Anxiety and stress 
related to sleep deprivation has been documented, along with changes in the daily routines of night shift workers (Young 1998; Gagwisch et al. 2006; Sabanayagam et al. 2010). It has also been reported that long term exposure to increased BP, secondary to sleep deprivation, can cause the cardiovascular system to reset its normal BP level to that of a higher BP, causing the body to operate on an elevated BP level on a regular basis (Gagwisch et al. 2006). This is a probable concern for night shift workers due to their repeated night work (Bryden 1973; Culpepper 2010; Drake 2010).

\section{Sleep Duration in Shift Workers}

The average sleep time for Americans has been on a steady decline for past decade (Gagwisch et al. 2006; Pickering 2006b), and it has been reported that sleep disorders adversely affect cardiovascular health (Culpepper 2010; Drake 2010 et al.; Sabanayagam et al. 2010). The decrease in sleep has been attributed to the increased devotion to work and increased participation in extracurricular activity (Gagwisch et al. 2006; Pickering 2006b; Srivastava 2010). Night shift workers tend to sleep less during work days compared to day shift workers in general (Knauth et al. 1980; Akerstedt 1984). Sleep restriction and deprivation has been linked to an increased incidence of HTN in both the normotensive population and the already hypertensive population (Gangwisch et al. 2006). Night shift workers are particularly at risk for sleep deprivation or restriction due to their hours of work therefore increasing their odds for developing CVD (; Bryden 1973; Ostberg 1973; Knauth et al. 1980; Akerstedt 1984; Chau et al. 1989; Pickering 2006b; Sabanayagam et al. 2010).

\section{Anxiety}

Anxiety is an important indicator of psychological stress and well-being, and has been suggested to play a role in the development of CVD (Young 1998; Speilberger and Reheiser 2009). Anxiety is a normal consequence of psychological stress that can be healthy, but too much can be detrimental and negatively affect daily activities such as social interaction, sleep patterns and work activity. In fact, anxiety disorders have been 
reported to be more prevalent than any other mental health illness, affecting 40 million U.S. adults, and costing an average of 42 billion dollars per year to treat (Young et al 1998; National Institute of Mental Health 2010; Anxiety Association of America 2011).

Unlike other mental health disorders, anxiety can be reported as a trait or emotion brought on by a particular situation or problem (Speilberger 1970; Young et al. 1998; Speilberger and Reheiser 2009). Anxiety can be generated by situations such as family troubles, financial difficulty or repeated periods of work stress. This anxiety can cause an individual to experience many physical symptoms that include sweating, a racing heart, chest pain, troubled breathing and upset stomach (Anxiety Association of America 2011; National Institute of Mental Health 2011). Anxiety can also contribute to difficulty sleeping (Anxiety Association of America 2011). These symptoms can cause difficulties at work and may intensify during a work shift. The stressors of shift work such as work environment and changes to social habits outside of work may increase the frequency of mental health disorders and work related anxieties (Banahan 1979; White and Baker 1987). Previous research suggests that extended working hours, combined with incomplete recovery times, are important contributors to work related anxiety (Lo et al. 2008).

\section{Speilberger's State-Trait Anxiety Inventory}

With the development of standard questionnaires such as the Speilberger StateTrait Anxiety Inventory (STAI), one can assess anxiety levels in two forms. State anxiety is the measurement of the subjective feelings of tension, apprehension, nervousness, and worry associated with arousal at a specific moment, while trait anxiety is the measurement of anxiety proneness and increased feelings of anxiety that have built up in past months and or years (Speilberger 1970; Speilberger and Reheiser 2009; Young et al. 1998). Whitehead et al. (1977) reported anxiety and anger to be aggravating factors for increased blood pressure in the hypertensive population. Furthermore, White and Baker (1987) reported significant increases of both systolic and diastolic blood pressure in individuals experiencing panic attacks, which are a form of anxiety. It has also been 
proposed that repeated periods of increased stress may play a key role in the development of HTN and the long term development of CVD in normotensive individuals (Banahan et al. 1979; Chau et al. 1989; Young et al. 1998). There are, however, few studies that have been able to directly link work related anxiety to increased cardiovascular stress and HTN.

The present study aims to indentify fixed night shift work as a risk factor for the development of HTN. The demands of shift work such as high stress situations, reduced TST and altered regulatory functions may increase BP. We hypothesized that fixed 12 hour night shift work would negatively affect BP regulation, state anxiety levels and TST, as depicted in the following flow chart.

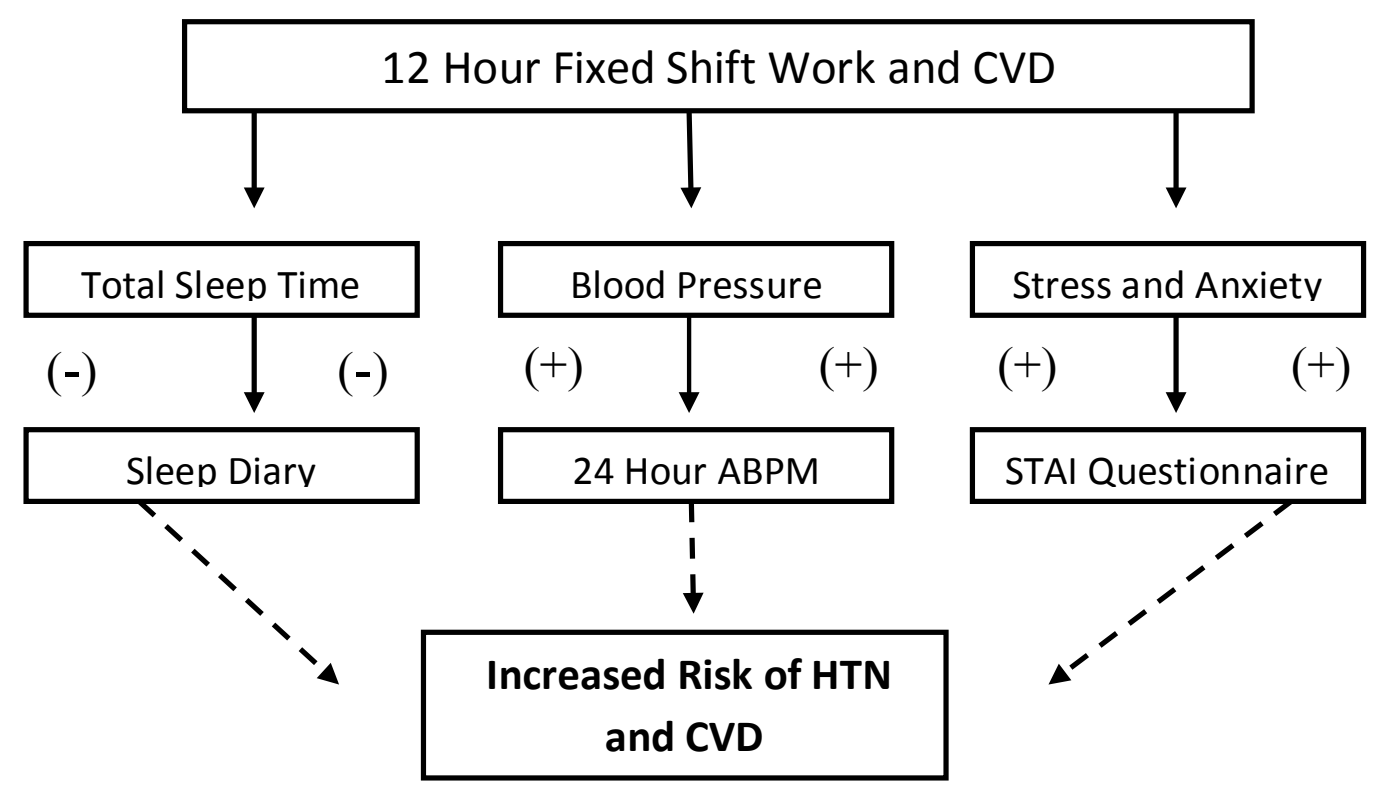

Figure 1. Fixed 12 hour shift work flow chart. The above flow chart describes the proposed effects that fixed 12 hour night shift work has on the human body and its development of hypertension (HTN) and cardiovascular disease (CVD). 


\section{Methods}

\section{Subjects}

Twenty eight adult healthcare workers (age 22-60 years) were recruited from two local hospitals (Aspirus Keweenaw Hospital, Laurium, MI and Portage Health, Hancock, MI) to participate in this study. Participants included physicians, physician assistants, nurses and emergency room staff who had worked regularly scheduled 12 hour fixed shifts for a minimum period of three months prior to testing. Two experimental groups were developed based off of shift type: 1) fixed 12 hour night shift ( $\mathrm{n}=15)$ and 2) fixed 12 hour day shift $(n=13)$. Subject baseline characteristics are outlined in Table 1. All subjects abstained from alcohol consumption and exercise 12 hours prior to and during testing. Exclusion criteria included pregnancy, smoking, diabetes, a history of heart problems and/or subjects who took any heart or blood pressure medication. The Michigan Technological University Institutional Review Board granted approval of this study prior to any testing (approval \#M0643), and all subjects provided written informed consent prior to participation.

Table 1.1

\section{Baseline subject characteristics.}

\begin{tabular}{lcc} 
Variable & $\begin{array}{c}\text { Night Shift } \\
(\mathbf{n}=\mathbf{1 5})\end{array}$ & $\begin{array}{c}\text { Day Shift } \\
(\mathbf{n}=\mathbf{1 3})\end{array}$ \\
\hline Age (yr) & $38 \pm 3$ & $45 \pm 2$ \\
Height $(\mathrm{cm})$ & $165 \pm 3$ & $166 \pm 3$ \\
Weight $(\mathrm{kg})$ & $71 \pm 3$ & $74 \pm 3$ \\
BMI $\left(\mathrm{kg} / \mathrm{m}^{2}\right)$ & $26 \pm 1$ & $26 \pm 1$ \\
Resting SAP (mmHg) & $120 \pm 3$ & $124 \pm 4$ \\
Resting DAP (mmHg) & $76 \pm 2$ & $75 \pm 3$ \\
Experience (months) & $57 \pm 14$ & $50 \pm 13$ \\
\hline
\end{tabular}

Values are means \pm SE; n, number of subjects; BMI, body mass index; SAP, seated systolic arterial blood pressure; DAP, seated diastolic arterial blood pressure. 


\section{Experimental Design}

Anthropometric measurements and subject information were recorded for each subject (height, weight, resting seated BP, etc.) on the first day of testing. Participants were fitted and instructed on proper use of the 24 hour ABPM. Appropriate sized BP cuffs were selected and applied to the non-dominant arm proximal to the brachial artery within 60 minutes prior to the scheduled work shift or the corresponding time on the nonwork (off) day of testing. Care was taken to start the corresponding non-work day measurement during the same time of day (i.e. workday measurement started 6:45 am, non-work day test also started at 6:45 am). All subjects were tested twice: once on a work day and once on a non-work (off) day in a randomized order. Work day testing began after a participant had been on their work schedule for at least 48 hours (i.e. work day \#3), and off day testing started at least 48 hours after completion of their last working day (i.e. off day \#3).

During testing days, each subject recorded their sleep and wake times in a sleep diary immediately after waking in the morning. Participants also completed a caffeine intake diary recording total ounces of caffeine consumed per test period and a STAI state anxiety questionnaire on each day of testing just prior to reporting to bed. Caffeine intake was similar across testing days and between groups (time*group interaction: $\mathrm{p}=0.38$ ). Subjects reported back to the laboratory after the 24 hour test period was complete.

\section{Measurements}

ABPMs (SpaceLabs Healthcare, 90207 model) were used to assess 24 hour BP once during a work day and once during an off day as outlined above. Subjects were given the choice to wear the monitor around the waist or over the shoulder, depending on their comfort. The ABPM device was then started, and readings were taken during the next 24 hour period. Measurements were taken every twenty minutes during wake time and every thirty minutes during non-wake time (to minimize sleep disruption), and the ambulatory BP monitor was set to inflate to a maximum of $220 \mathrm{mmHg}$. 
The Spielberger State-Trait Anxiety Inventory (STAI) is a standardized anxiety index first published in 1970 (Speilberger 1970; Tilton 2008). This study evaluated state anxiety by having participants complete the Y-1 form of the Spielberger State-Trait Anxiety Inventory (STAI) each testing day prior to going to bed (Spielberger 1983). Finally, a sleep diary was used first thing in the morning to record their bedtime and awake time. No sleep disturbances were reported on testing nights and TST was evaluated by investigators to the nearest 10 minute average.

Data from the 24 hour ABPM was analyzed via SpaceLabs Healthcare Report Management System (version 3.0.0). Sleep times were adjusted in the SpaceLabs Report Monitoring system based off of the self reported sleep diary. Data were analyzed with SPSS statistical software (SPSS, version 18.0, Chicago, IL). Analyses of BP variables and sleep times were performed using two-way repeated measures analysis of variance. The between subject factor was night shift versus day shift and the within subject factor was work day versus non-work day. Post hoc analyses were performed when appropriate with least paired T-tests. The relationship between TST, state anxiety and BP variables were examined by Pearson's correlation analysis. Significant differences were noted when $\mathrm{p}<0.05$. All results are listed as means \pm standard errors.

\section{Results}

Figure 2 reveals combined total sleep time for both test periods is similar between the fixed night shift and fixed day shift workers. However, night shift workers had significantly less TST on work days versus off days $(345 \pm 20$ vs. $552 \pm 30$ minutes; $\mathrm{p}<0.001$ ) as demonstrated in Figure 3. In contrast, no statistical difference was found in TST for day shift workers (475 \pm 15 vs. $437 \pm 20$ minutes) between a work and an off day respectively. Lastly, the extent of change in TST (work vs. off day) was not affected by months of experience for each of the shift working groups ( $\mathrm{p} \geq 0.582$ for both night and day shift workers). Likewise, the delta for all of the BP variables and HR (i.e. work vs. off day) were unaffected by the total amount of work experience ( $\mathrm{p} \geq 0.177$ for all). 


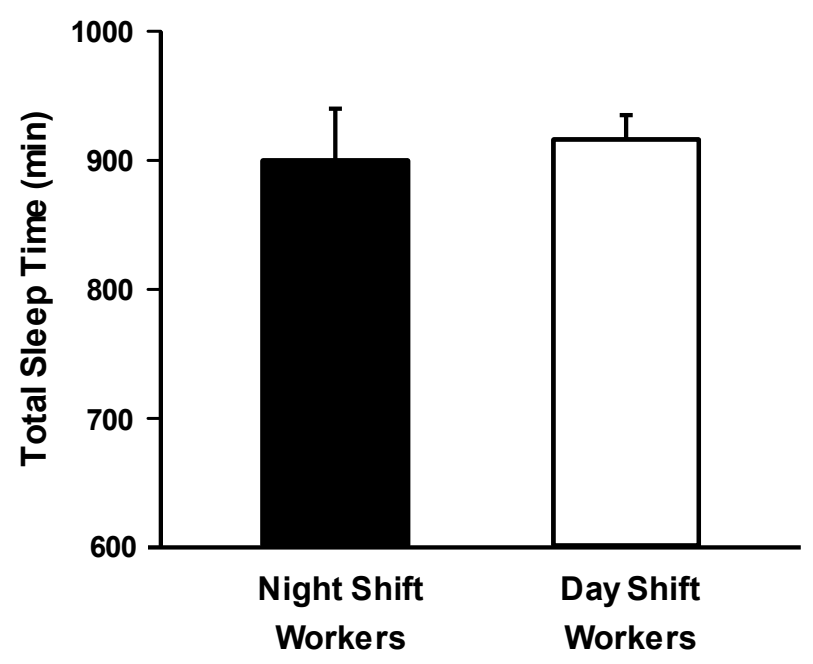

Figure 2. Combined sleep times for night and day shift workers. Combined total sleep time (work day plus off day) was similar in night shift workers and day shift workers.

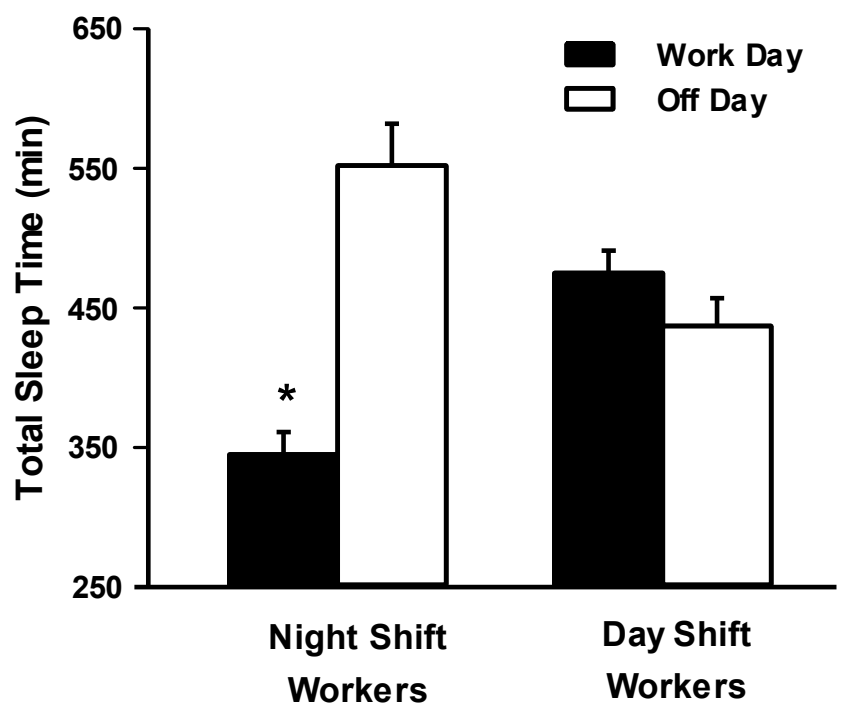

Figure 3. Total sleep time, work day versus off day. Total sleep time was significantly $(* \mathrm{p}<0.01)$ lower for night shift workers on work days compared to off days, whereas day shift workers had similar total sleep time on both days. 
Statistically significant increases were found for 24 hour SAP, DAP, MAP and HR ( $\mathrm{p} \leq 0.01$ for all) in the night shift group during a work day compared to an off day as indicated in Figure 4. In contrast, there were no significant BP or HR differences present in the day shift workers when comparing work and off days. Table 2 displays BP variables for each group and for each test period (work vs. off day).
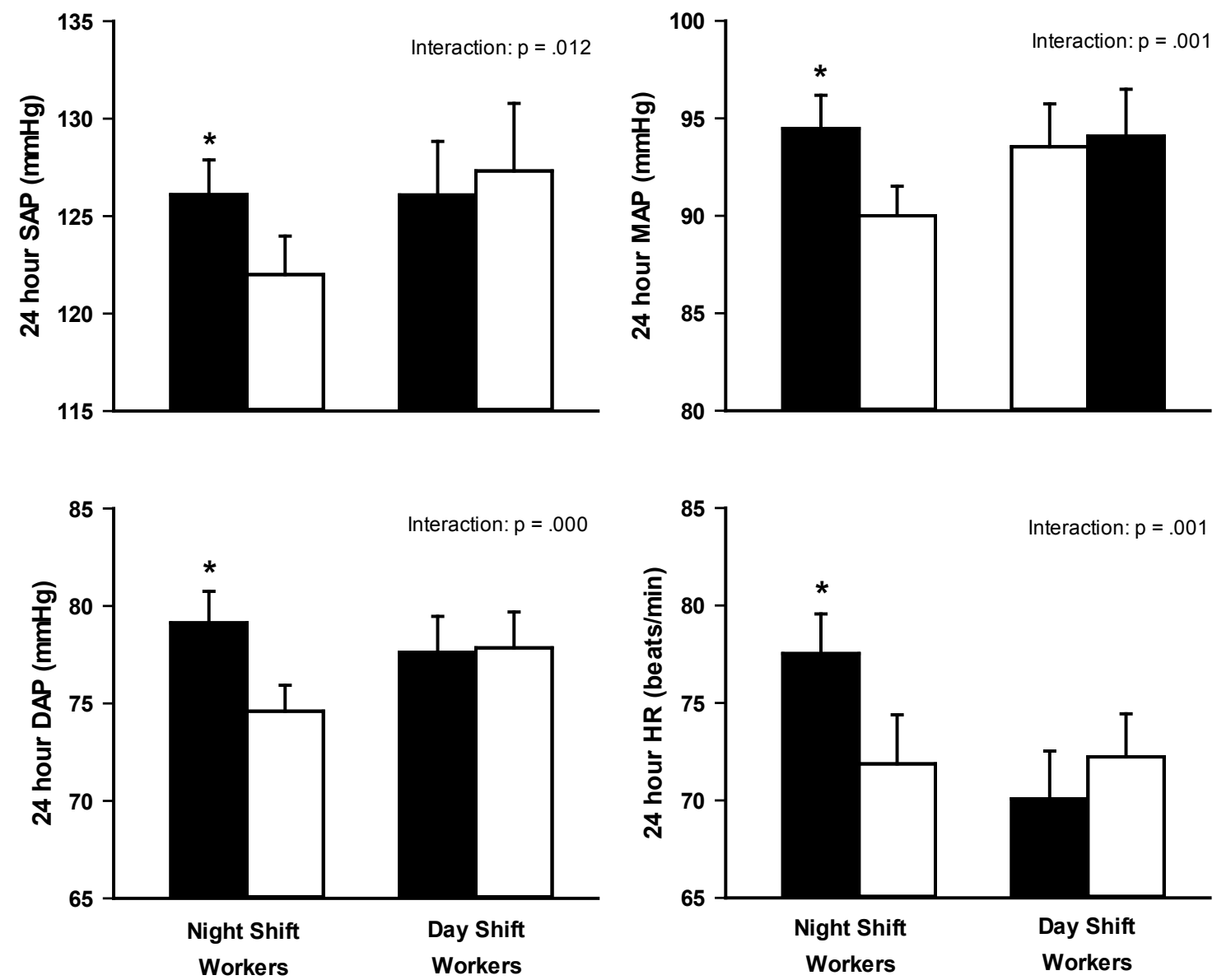

Figure 4. 24 hour SAP, DAP, MAP and HR, work day versus off day. 24 hour systolic arterial pressure (SAP), diastolic arterial pressure (DAP), mean arterial pressure (MAP) and heart rate (HR) was significantly $(* \mathrm{P}<0.05)$ higher on work days than off days in fixed night shift workers. Fixed day shift workers were similar for all variables on work and off days. 


\section{Table 1.2}

24 hour blood pressure and heart rate, off day versus work day.

Night Shift $(n=15) \quad$ Day Shift $(n=13)$

\begin{tabular}{lccccc} 
Variable & Off day & Work day & Off day & Work day & Time*Group \\
\hline SAP (mmHg) & $122 \pm 2$ & $126 \pm 2 *$ & $127 \pm 3$ & $126 \pm 3$ & $p=0.01$ \\
DAP (mmHg) & $75 \pm 1$ & $79 \pm 2 *$ & $78 \pm 2$ & $78 \pm 2$ & $p<0.01$ \\
MAP (mmHg) & $90 \pm 2$ & $94 \pm 2 *$ & $94 \pm 2$ & $94 \pm 2$ & $p<0.01$ \\
HR (beats/min) & $72 \pm 3$ & $78 \pm 2 *$ & $72 \pm 2$ & $70 \pm 2$ & $p<0.01$
\end{tabular}

$\overline{\text { Values are mean } \pm \text { SE; SAP, } 24 \text { hour systolic arterial blood pressure; DAP, } 24 \text { hour diastolic }}$ arterial blood pressure; MAP, 24 hour mean arterial blood pressure; HR, 24 hour heart rate. $*_{\mathrm{p}}<0.01$, work day vs. off day.

State-anxiety scores did not differ on work and off days for either group (time*group interaction, $\mathrm{p}=0.248$ ) as shown in Figure 5. There was not a significant relationship $(p=0.896)$ between changes in state anxiety and changes in total sleep time from an off day to a work day as demonstrated in Figure 6. However, changes in SAP, DAP and MAP were correlated $(\mathrm{P}<0.01$ for all) to changes in total sleep time from an off day to a work day as shown in Figure 7. 


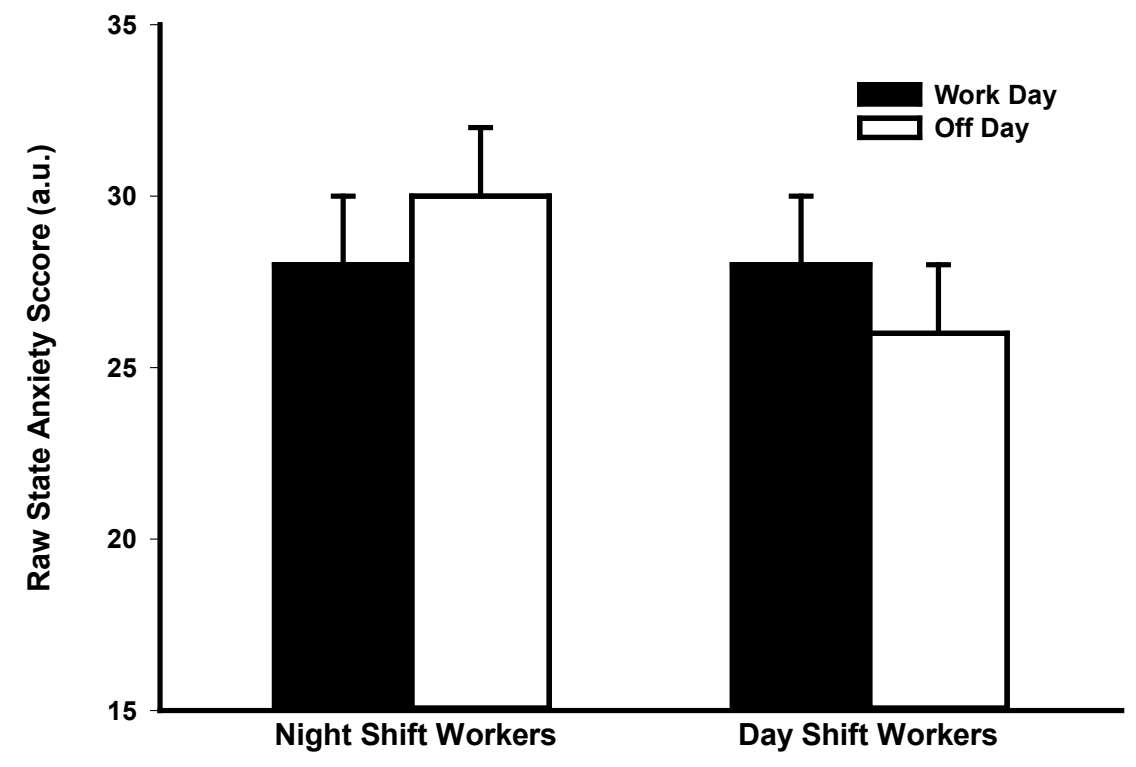

Figure 5. Raw state anxiety scores, work day versus off day. There is no significant change in state anxiety levels between the work day and off day in either the fixed night shift or fixed day shift workers.

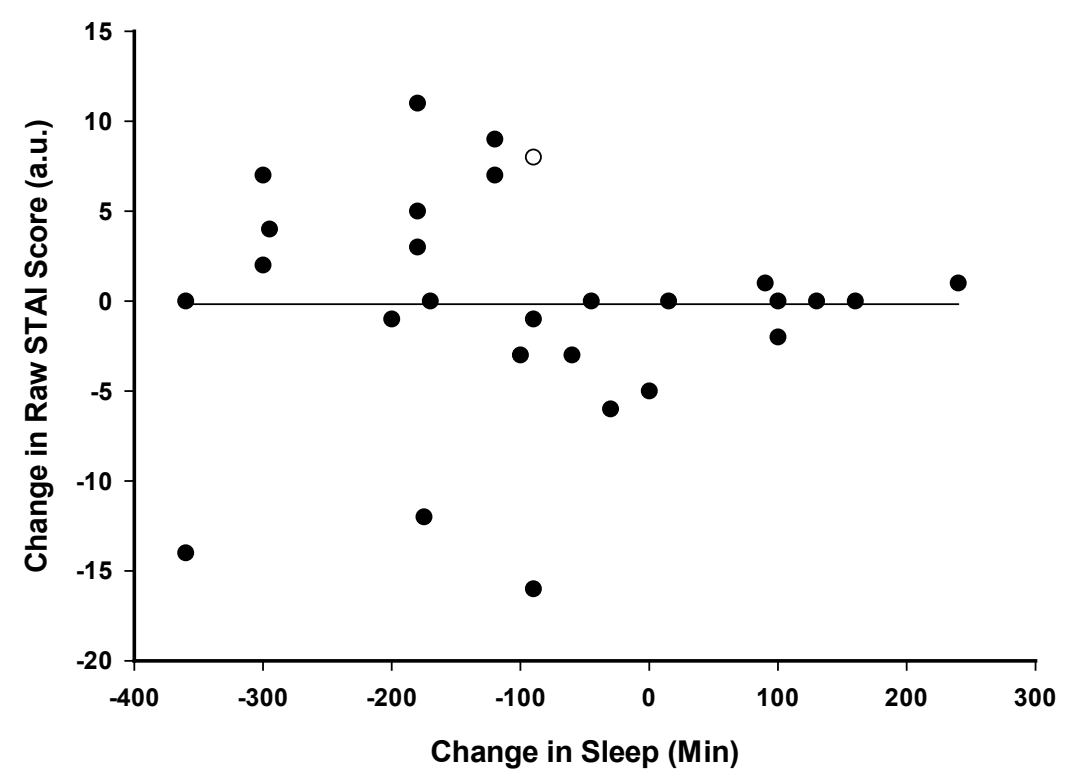

Figure 6. $\Delta$ Total sleep time and $\Delta$ state anxiety scores, work day versus off day. There is no relationship $(\mathrm{R}=0.896, \mathrm{P}=0.248)$ between the change in state anxiety and TST from off day to work day. 

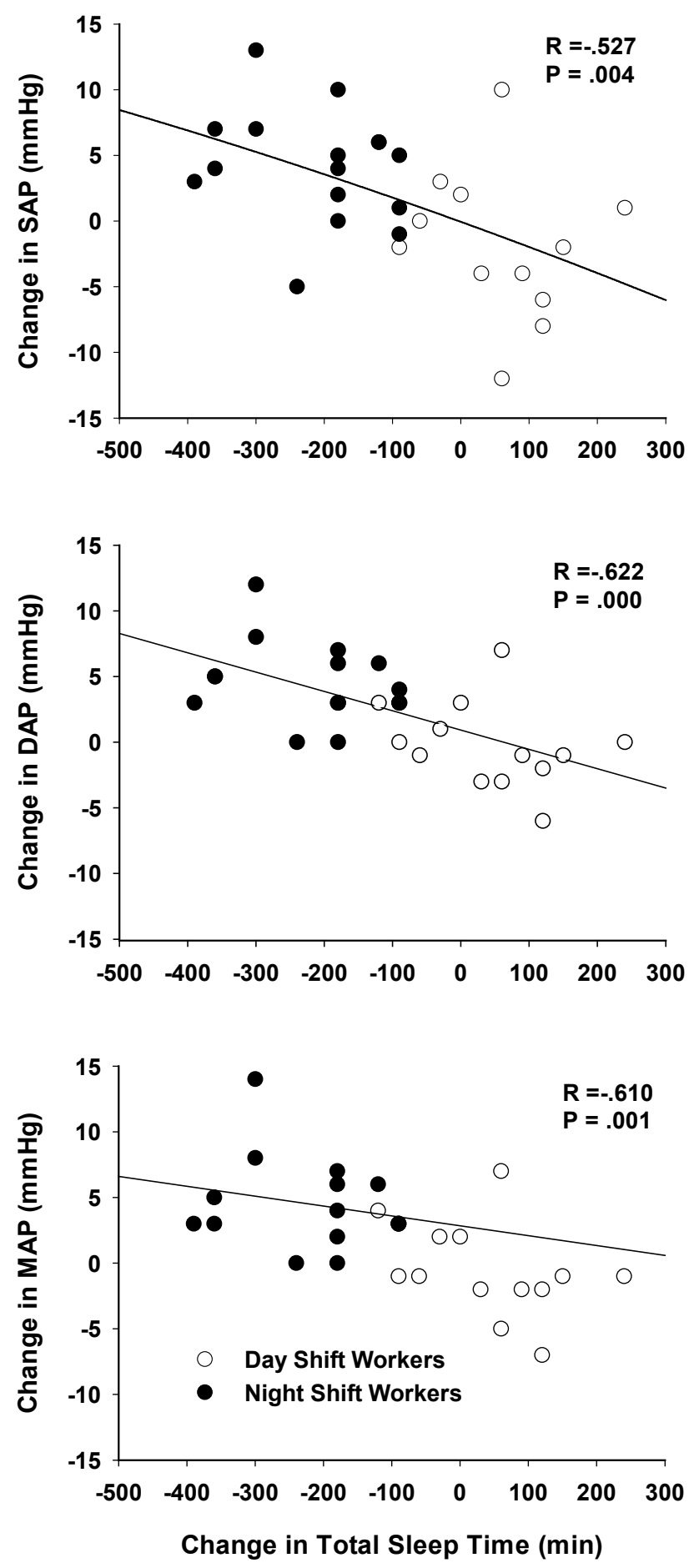

Figure 7. $\Delta$ Total sleep minutes and $\Delta \mathbf{B P}$, work day versus off day. Changes in systolic arterial pressure (SAP), diastolic arterial pressure (DAP) and mean arterial pressure (MAP) were related to change in Total Sleep Time (off day vs. work day). 


\section{Discussion}

Three primary findings have emerged from the current investigation. First, fixed shift work causes disruption to the sleeping pattern of fixed 12 hour night shift workers, drastically decreasing TST on a work day compared to an off day. In contrast, TST was similar on work and off days in the fixed 12 hour day shift workers. Second, fixed 12 hour night shift workers have increased 24 hour BP (SAP, DAP, MAP) and HR during the 24 hour period in which they worked, while day shift workers had similar BP and HR on work and off days. Finally, changes in the 24 hour BP profiles of fixed shift workers are related to the decreases in TST on the work day and not due to changes in short term anxiety. These findings suggest that 12 hour fixed night shift work negatively affects acute blood pressure regulation via disruption of the normal sleep-wake cycle, which may increase the long-term risk for the development of HTN and CVD. To our knowledge this is the first study to report the effects of 12 hour night shift work on TST, state-anxiety levels and 24 hour BP regulation.

Sleep restriction has been identified as a potential health risk to those who participate in shift work (Sack et al 2007; Lo et al. 2008; Su 2008 et a.; Sabanayagam et al. 2010). Reduction in TST with night shift work has been noted in previous studies, but in the context of impaired performance and sleepiness (Akerstedt 1995, 2003). Excessive sleepiness during night shift work and insomnia during the day time sleep period has been classified as 'shift work sleep disorder' (Drake et al. 2004). This disorder may occur in $10 \%$ or more of night shift workers (Drake et al. 2004; Waage et al. 2009), but the normal versus pathological response to night shift work is difficult to diagnose (Sack et al. 2007). The diagnosis and recognition of sleep disorders is becoming increasingly high as the number of disorders, such as insomnia and excessive sleepiness, has become a huge economic burden. The cost of covering work-related accidents in the United States in 2009 was between 18 and 24 billion dollars (Culpepper 2010). Culpepper (2010) also reports the odds of medical residents receiving percutaneous injury, from a needle or scalpel, to be twice as high for those working night shift compared to those on day shift. 
The current study has a primary focus on 24 hour BP and cardiovascular risk rather than measures of work-related performance or sleep disorders. Nevertheless, the present study is consistent with previous studies noting that night shift work can reduce TST (Akersedt 1995, 2003). It is also significant that the fixed night shift workers in the present study appear to attempt catching up on sleep during off-days. Because these workers tend to get less than 7 hours of sleep on their work days and more than 9 on their off days, they may be increasing their risk for HTN and CVD (Gottlieb et al. 2006; Sabanayagam et al. 2010).

Shift work has been linked to HTN, making this is a novel area of research. To our knowledge two previous studies have reported that night shift work increases 24 hour BP in comparison to day shift workers (Ohira et al. 2000; Su et al. 2008), while two other studies report that 24 hour BP is increased during a work day in night shift workers versus an off day (Adams et al. 1998; Lo et al. 2008). These previous studies regarding night shift workers and 24 hour BP have some methodological concerns that preclude conclusive results and none of them specifically compared fixed 12 hour night shift workers to fixed 12 hour day shift workers. Consistent with Adams et al. (1998) and Lo et al. (2008), the present study indicates that 12 hour night shift workers have increased 24 hour BP on work days versus off days. While the two aforementioned studies (Adams et al. 1998; Lo et al. 2008) did not detect a difference in HR between testing days, the current study demonstrated an increase in HR on work days in the fixed night shift workers. In contrast, the day shift workers (i.e. the control) in this study did not experience increases in 24 hour BP profiles or changes in HR during work days, which is similar to previous studies (Lo et al. 2008; Su et al. 2008). Based on our results 12 hour fixed night shift workers may be at increased risk of developing CVD due to increased 24 hour BP and HR on work days.

Diastolic HTN is typically present in the under 50 population and tends to remain stable or decrease after that age (Rochella et al. 2003). Information regarding the importance of systolic HTN has become more prevalent with the increase of age, more 
commonly in those over 50 years of age (Kannel 2000). The JNC 7 (2003) reports systolic HTN to be the most important, noting that an increase of $20 \mathrm{mmHg}$ doubles the mortality rate for stroke and ischemic heart disease in individuals over the age of 50 . Night shift worker's SAP was elevated by about $4 \mathrm{mmHg}$ on work days in the present study. Recall that the average age of the night shift workers was only 38 years, leaving the possibility for SAP to become increasingly elevated by age 50. Night shift work may contribute to increased hemodynamic risk and anxiety, putting night shift workers at risk for the development of HTN and sleep disorders (Bryden 1973; Culpepper 2010; Drake 2010; Schwartz 2010). The present study is the first to compare the increases in 24 hour BP during the work day vs. off day to the TST and state anxiety responses over the same period.

Previous findings have indicated that the presence of increased vascular stress during night shift work may increase the frequency of mental health disorders and work related anxieties (Lo et al 2008). Stressors encountered during fixed 12 hour night shift work include work environment, sleep deficit, and changes to social habits outside of work. Whitehead (1977) reported anxiety and anger as aggravating contributors to increased BP in the hypertensive population. Furthermore, White and Baker (1987) reported significant increases of both systolic and diastolic BP in individuals experiencing panic attacks, a form of anxiety. It has also been proposed that repeated periods of increased stress may be an important predictor of BP levels and play a key role in the long-term development of HTN and CVD (Banahan 1979; Chua et al. 1989; Young 1998; Lo 2008 et al.).

State anxiety levels and TST were analyzed in relationship to 24 hour BP profiles in the present study, giving us the ability to compare and contrast work and off days in the shift working population. Prior studies have implied that shift work may induce psychological changes that may increase the risk for CVD (Akerstedt 1990; Knutsson 2003), but the potential association between psychological changes and changes in 24 hour BP has not been assessed in fixed shift workers. The results of the present study 
indicate that 12 hour fixed shift work did not alter state-anxiety (i.e. work day vs. off day). Thus changes in 24 hour BP were not associated with changes in state-anxiety. The results of this study are consistent with similar studies that have demonstrated night shift workers are at risk for the development of HTN due to increased BP and increased vascular stress and that anxiety does not play a major role (Knuttson 2003; Lo et al 2008; $\mathrm{Su}$ et al 2008). Conversely, changes in 24 hour BP from the off day to work day were linked to changes in TST. This is represented by our Pearson's correlation values for TST versus SAP, DAP and MAP respectively $(\mathrm{R}=-0.53, \mathrm{R}=-.062$ and $\mathrm{R}=-0.61)$. Thus, the restriction of sleep on work days directly contributes to increases in 24 hour BP for 12 hour fixed shift workers.

A recent review on shift work and CVD highlighted the need for future studies to have robust study design, to address fixed shift workers, and to examine the potential stress related factors of shift work (Boggild 2009). Boggild (2009) specifically noted that the next review on shift work and heart disease, due in 2019, must include higher quality studies. The current study has attempted to address many concerns from previous studies. The present study design is robust by comparing fixed 12 hour night shift workers and fixed 12 hour day shift workers of a similar job type, allowing for at least 48 hours between the randomized (crossover) testing, and comparing work days to off days in these fixed 12 hour shift workers. Lastly this study had very particular exclusion criteria so that the two subject groups were controlled as much as possible for everything but their shift type. Exclusion criteria included things such as pregnancy, history of heart problems, smoking and the use of any prescription heart or BP medication. Finally, to our knowledge this is the first study to examine and report the effects of 12 hour fixed night shift work on state anxiety levels, TST and 24 hour regulation of BP.

Our findings suggest that night shift work causes disruption of the normal sleepwake cycle, negatively affects acute BP regulation, and potentially increases the long term risk of CVD. The present study also suggests that TST may be an integral part of acute BP regulation. Contrary to our hypothesis, state anxiety levels did not have an 
effect on acute BP regulation during night shift work, but decreased TST did affect 24 hour BP regulation. This is demonstrated by our significant correlation values for TST versus 24 hour BP. The current study provides insight on the effects that fixed shift work has on the human body. These findings should be used to implement changes to minimize the development of HTN, long term CVD and other ill health effects in shift workers.

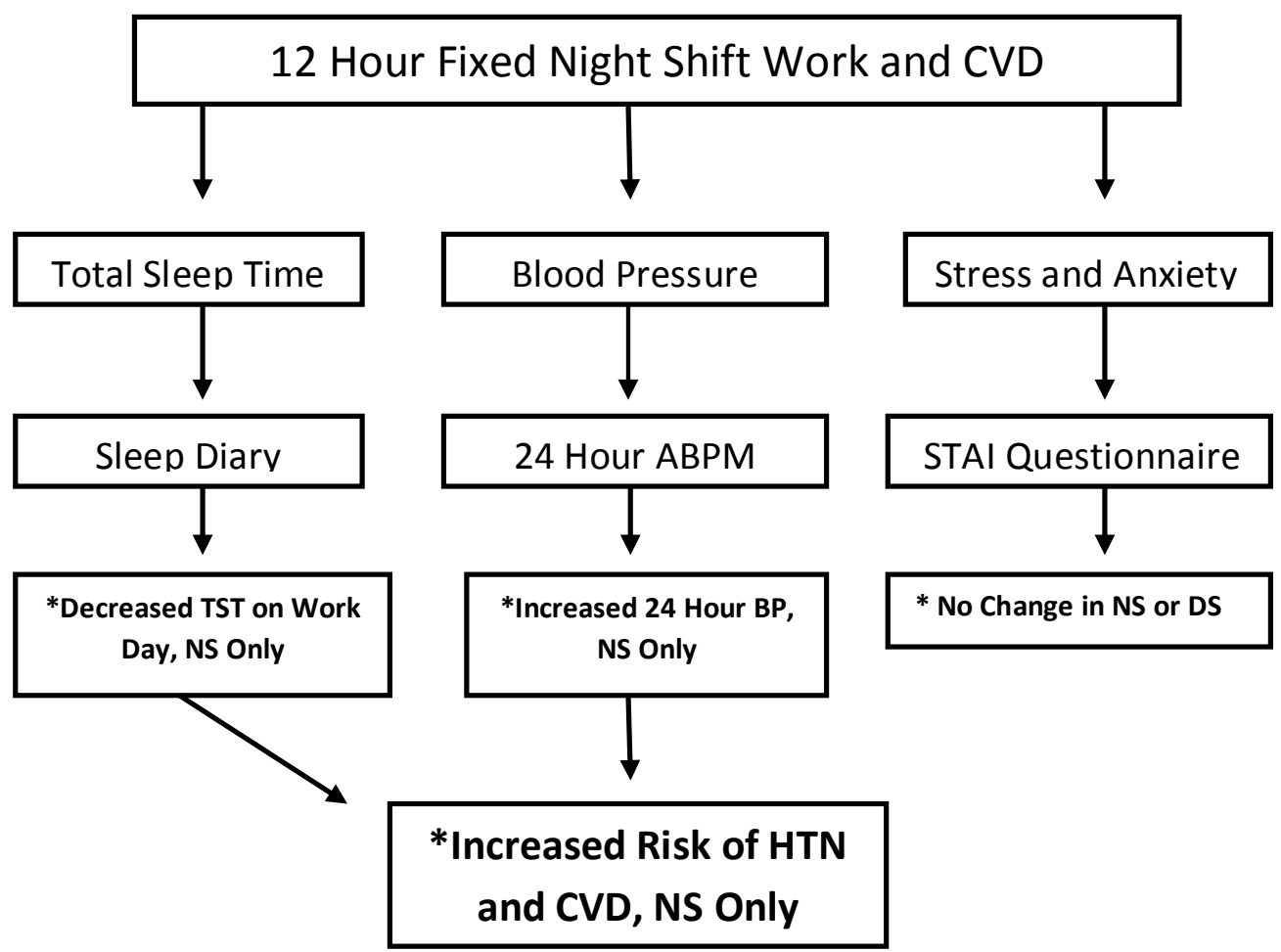

Figure 8. Study Specific Night Shift Work Flow Chart. This revised flow chart indicates that decreased total sleep time and increased 24 hour blood pressure likely contribute to the increased risk of hypertension (HTN) and cardiovascular disease (CVD) for fixed 12 hour night shift workers. It does not appear that work-related changes in state-anxiety play a significant role in the risk for HTN and CVD in night shift workers. 


\section{Clinical Implications/Areas of Future Research}

With such a large portion of the American population participating in shift work it is important to have the suggestions and educational resources to improve the overall health and well-being of shift workers. For example, increasing TST on work days may improve 24 hour BP regulation, and decrease the overall effects of night shift work.

Future research should include a longitudinal study design. One goal could be to keep the same subject groups and monitor them again in 6 months intervals. This would allow for a more accurate evaluation of long-term effects in fixed 12 hour night shift work. This study could also test three work days and three off days to improve the accuracy of measurements. Different departments throughout the hospital, (i.e. Emergency, Obstetrics, Medical Surgery), should also be examined to determine if there are significant departmental differences that could possibly influence any of the variables examined in the present study. Finally, research in minority populations should also be considered due to the varied prevalence of HTN across different racial groups. It has been

documented that HTN is more prevalent in African Americans, while Native American and Mexican Americans have lower HTN rates (Roccella et al. 2003). 


\section{Limitations}

Three potential limitations to this study should be recognized. First, 24 hour BP, TST and anxiety were examined once on a work day and once on an off day. It may be advantageous to test 12 hour fixed shift workers on more than one occasion, but these healthcare workers reported that these testing days were typical work and off days. Second, TST was recorded via a sleep diary and not actigraphy. This should not be a major limitation however, as sleep diaries are considered to be a valid assessment tool for TST in shift workers (Sack et al. 2007). Finally, scheduling of the night and day shift staff was not manipulated by our study, which could also be considered a limitation. 


\section{Bibliography}

Adams, S.L. Ambulatory blood pressure and holter monitoring of emergency physicians before, during, and after a night shift. Academic Emergency Medicine. 5(9):871$877,1998$.

Anixiety Disorders Association of America (ADAA). http://www.adaa.org. 2011.

Akerstedt, $\mathrm{T}$ et al. Shift Work and Cardiovascular Disease. Scandanavian Journal of Work and Environmental Health. 10(6): 409-414, 1984.

Akerstedt, T. Psychological and psychophysiological effects of shift work. Scandanavian Journal of Work and Environmental Health 16 Suppl 1: 67-73, 1990.

Akerstedt, T.Work hours, sleepiness and the underlying mechanisms. Journal of Sleep Research 4(S2): 15-22, 1995.

Akerstedt, T. et al. Sleepiness and Days of Recovery. Transportation Research Part F; Traffic Psychology and Behavior. 3(4): 251-261, 2000.

Akerstedt, T. Shift work and disturbed sleep/wakefulness. Occupational Medicine (London) 53(2): 89-94, 2003.

Akerstedt, T. Wright, K. P. Sleep Loss and Fatigue in Shift Work and Shift Work Disorder. Journal of Clinical Sleep Medicine. 4(2): 257-271, 2009.

American Heart Association. http://www.heart.org, 2011.

Appel et al 1997. A Clinical Trial of the Effects of Dietary Patterns on Blood Pressure. New England Journal of Medicine. 336: 1117-1124, 1997.

Aschoff, J. Circadian Rhythms in Man. Science. 148: 1427-1432, 1965.

Banahan, B.F. Hypertension and stress: A preventative approach. Journal of Psychosomatic Research. 23: 69-75, 1979. 
Boggild, H. and Knutsson A. Shift work, risk factors and cardiovascular disease. Scandinavian Journal of Work and Environmental health 25(2): 85-99, 1999.

Bryden, G., Holdstock, T.L. Effects of Night Duty on Sleep Patterns of Nurses. Psychophysiology. 10(1): 36-42, 1973.

Centers for Disease Control and Prevention (CDC). http://www.cdc.gov, 2011.

Chau, N. et al. Twenty-Four-Hour Ambulatory Blood Pressure in Shift Workers. Circulation. 80:341-347, 1989.

Culpepper, L. The social and economic burden of shift-work disorder. Journal of Family Practice. 59(1 Supplement): S3-S11, 2010.

Dawber, T.R and Kannel, W.B. The Framingham Study an epidemiological approach to coronary heart disease. Circulation. 34:553-555, 1966.

Dawson, T. et al. Long working hours, safety and health: toward a national research agenda. NIOSH, 2004.

Drake, C. L. The characterization and pathology of circadian rhythm sleep disorders. Journal of Family Practice 59(1 Supplement): S12-17, 2010.

Drake, C.L. et al. Shift work sleep disorder: Prevalence and consequences beyond that of symptomatic day workers. Henry Ford Hospital Sleep Disorders and Research Center. SLEEP. 27(8), 2004.

Fries, E. Hemodynamics of Hypertension. Physiological Reviews. 40(1): 27-54, 1960.

Gangwisch et al. Short sleep duration as a risk factor for hypertension: analyses of the first national health and nutrition examination survey. Hypertension. 47: 833-839, 2006.

Gottlieb, D. J. et al. Association of usual sleep duration with hypertension: the Sleep Heart Health Study. Sleep 29(8): 1009-1014, 2006. 
Guyton, A.C. Blood Pressure Control-Special Role of the Kidneys and Body Fluids. Science. 252(5014): 1813-1816, 1991.

Guyton, A.C. et al. Arterial Pressure Regulation: Overriding Dominance of the Kidneys in Long-Term Regulation and in Hypertension. The American Journal of Medicine. 52(5): 584-594, 1972.

Guyton, A. C. and J. E. Hall. Textbook of medical physiology. Philadelphia, Elsevier Saunders, 2006.

Harrington, J.M. Shift work and health: a critical review of the literature. H.M.S.O. 2-20, 1978.

Harrington, J.M. Health effects of shift work and extended hours of work. Occupational Environmental Medicine. 58:68-72, 2001.

Health of Munitions Worker Committee. Final Report. H.M.S.O. London. 1918.

Johns, M. Reliability and Factor Analysis of the Epworth Sleepiness Scale. Sleep. 15(4): 376-381, 1992.

Kannel, W.B. Elevated systolic blood pressure as a cardiovascular risk factor. The American Journal of Cardiology. 85(2): 251-255, 2000.

Kawachi et al. Prospective study of shift work and the risk of coronary heart disease in women. Circulation 92:3178-82, 1995.

Knauth, P. Duration of sleep depending on the type of shift work. International Archives of Occupational and Environmental Health. 46: 167-177, 1980.

Knutsson, A. Health disorders of shift workers. Occupational Medicine. 53(2): 103-108, 2003.

Korner, P.I. Integrative neural cardiovascular control. Physiological Review. 51 (2): 312$367,1971$.

Lloyd-Jones, D. AHA Statistical Update: Heart Disease and Stroke Statistics. 2010. 
Lo, S. H. et al. Dynamic BP changes and recovery under different work shifts in young women. American Journal of Hypertension. 21(7): 759-764, 2008.

Nagai, M., Hoshide, S., and Kario, K. Sleep Duration as a Risk Factor for Cardiovascular Disease- A Review of the Recent Literature. Current Cardiology Reviews. 6: 5464, 2010.

Navar, G.L. Activation of the Intrarenal Renin-Angiotensin System is the Dominant Contributor to Systemic Hypertension. Journal of Applied Physiology. 111(4): 231, 2011.

National Institute of Mental Health. www.nimh.gov, 2011.

O'Brien, E. Ambulatory BP measurement: the case for implementation in primary care. Hypertension. 51(6): 1435-1441, 2008.

O'Brien, E. Accuracy of the SpaceLabs 90207 determined by the British Hypertension Society Protocol. Journal of Hypertension. Supplement 5: S25-S31, 1991.

Ohira, T. Effects of shift work on 24-hour ambulatory blood pressure and its variability among Japanese workers. Scandinavian Journal of Work and Environmental Health. 26(5): 421-426, 2000.

Ostberg, O. Inter-individual differences in circadian fatigue patterns of shift workers. British Journal of Industrial Medicine. 30(4) 341-351, 1973.

Pickering, T.G. Ambulatory blood pressure monitoring. New England Journal of Medicine. 354: 2368-2374, 2006. A

Pickering, T.G. Could Hypertension Be a Consequence of the 24/7 Society? The Effects of Sleep Deprivation and Shift Work. The Journal of Clinical Hypertension. 8(11): 819-822, 2006. B

Rocella, E.J. The Joint National Committee for the prevention, detection, evaluation and treatment of high blood pressure. 2010. 
Rowell, L.B., Human Cardiovascular Control. Oxford University Press, New York, NY. 1993.

Sabanayagam et al. Sleep duration and cardiovascular disease: Results from the national health interview survey. Sleep 33(8): 1037-1042, 2010.

Sack, R. L. et al. Circadian rhythm sleep disorders: part I, basic principles, shift work and jet lag disorders. An American Academy of Sleep Medicine review. Sleep 30(11): 1460-1483, 2007.

Schwartz, J. R. Recognition of shift-work disorder in primary care. Journal of Family Practice 59 (Supplement): S18-23, 2010.

Spielberger, C. D., Gorsuch, R.L., and Lushene. R.E. Manual for the State-Trait Anxiety Inventory. Palo Alto, CA: Consulting Psychologists Press, 1970.

Spielberger CD. Manual for the State-Trait Anxiety Inventory. Palo Alto, CA: Consulting Psychologists Press, 1983.

Speilberger, C.D. and Reheiser, E.C. Assesment of emotions: Anxiety, Anger, Depression, and Curiosity. Applied Psychology: Health and Well-Being. 1(3): 271-302, 2009.

Srivastava, U.R. Shift Work Related to Stress, Health and Mood States: A Study of Dairy Workers. Journal of Health Management. 12 (2): 173-200, 2010.

Staessen et al. Task force IV: clinical use of ambulatory blood pressure monitoring. Blood Pressure Monitoring. 4(6), 1999.

Strokeassociation.org. When the beat is off. Stroke Connection Jan/Feb 2004.

$\mathrm{Su}$, T.C. et al. Elevated blood pressure, decreased heart rate variability and incomplete blood pressure recovery after 12-hour night shift work. Journal of Occupational Health. 50: 380-386, 2008.

Tilton, S.R. A Review of the State-Trait Anxiety Index. NewsNotes. 48(2), 2008. 
U.S. Department of Health and Human Services, National Institutes of Health, National Heart, Lung and Blood Institute. The seventh report of the joint national committee on: Prevention, Detection, Evaluation and Treatment of High Blood Pressure. Hypertension. 42:1206, 2003.

Waage, S. et al. Shift work disorder among oil rig workers in the North Sea. Sleep 32(4): 558-565, 2009.

White, W.B. and Baker, L.H. Ambulatory blood pressure monitoring in patients with panic disorder. Archives of Internal Medicine. 147: 1973-1975, 1978.

Whitehead, W.E. et al. Anxiety and anger in hypertension. Journal of Psychosomatic Research. 21:383-389, 1977.

Young, E.A. et al. Anxiety and cardiovascular reactivity in the Tecumseh population. Journal of Hypertension. 16: 1727-1733, 1998. 
APPENDIX A: Raw data - see included CD

APENDIX B: Original Repeated Measures ANOVA (28 subjects)

REPEATED MEASURES ANOVA

24 Hour SAP

$\underline{\text { Within-Subjects Contrast }}$

\begin{tabular}{lccccc} 
& Sum of Squares & df & Mean Square & F & Sig. \\
\hline Work Shift & 28.00 & 1 & 28.004 & 2.107 & .159 \\
Work Shift * Group & 97.71 & 27 & 97.719 & 7.351 & .012 \\
Total & 125.71 & 28 & & &
\end{tabular}

24 Hour SAP

Within-Subjects Effects

\begin{tabular}{|c|c|c|c|c|c|c|}
\hline \multirow[b]{2}{*}{ Source } & & \multirow{2}{*}{$\begin{array}{c}\text { Type III Sum of } \\
\text { Squares }\end{array}$} & \multicolumn{3}{|c|}{ Mean } & \multirow[b]{2}{*}{ Sig. } \\
\hline & & & df & Square & $\mathbf{F}$ & \\
\hline Time & Sphericity Assumed & 28.00 & 1 & 28.00 & 2.107 & .159 \\
\hline & Greenhouse- Geisser & 28.00 & 1 & 28.00 & 2.107 & .159 \\
\hline Time * & Sphericity Assumed & 97.71 & 1 & 97.71 & 7.351 & .012 \\
\hline Group & Greenhouse-Geisser & 97.71 & 1 & 97.71 & 7.351 & .012 \\
\hline
\end{tabular}




\section{Hour DAP}

$\underline{\text { With-in Subjects Contrast }}$

\begin{tabular}{lccccc} 
& Sum of Squares & df & Mean Square & F & Sig. \\
\hline Work Shift & 64.462 & 1 & 64.46 & 12.89 & .001 \\
Work Shift * Group & 79.033 & 1 & 79.03 & 15.80 & .000 \\
Total & 103.021 & 26 & & &
\end{tabular}

\section{Hour DAP}

\section{Within-Subjects Effects}

\begin{tabular}{|c|c|c|c|c|c|c|}
\hline Source & & $\begin{array}{c}\text { Type III Sum of } \\
\text { Squares }\end{array}$ & df & $\begin{array}{c}\text { Mean } \\
\text { Square }\end{array}$ & $\mathbf{F}$ & Sig. \\
\hline \multirow[t]{2}{*}{ Time } & Sphericity Assumed & 64.46 & 1 & 64.46 & 12.89 & .001 \\
\hline & Greenhouse- Geisser & 64.46 & 1 & 64.46 & 12.89 & .001 \\
\hline Time* & Sphericity Assumed & 79.03 & 1 & 79.03 & 15.80 & .000 \\
\hline Group & Greenhouse-Geisser & 79.03 & 1 & 79.03 & 15.80 & .000 \\
\hline
\end{tabular}




\section{Hour MAP}

$\underline{\text { With-in Subjects Contrast }}$

\begin{tabular}{lccccc} 
& Sum of Squares & df & Mean Square & F & Sig. \\
\hline Work Shift & 53.73 & 1 & 53.73 & 8.442 & .007 \\
Work Shift * Group & 87.23 & 1 & 87.23 & 13.70 & .001 \\
Total & 165.4 & 26 & & &
\end{tabular}

24 Hour MAP

Within-Subjects Effects

Type III Sum of Mean

\begin{tabular}{llccccc} 
Source & & Squares & df & Square & F & Sig. \\
\hline Time & Sphericity Assumed & 53.72 & 1 & 53.72 & 8.442 & .007 \\
& Greenhouse- Geisser & 53.72 & 1 & 53.72 & 8.442 & .007 \\
Time * & Sphericity Assumed & 87.23 & 1 & 87.23 & 13.70 & .001 \\
Group & Greenhouse-Geisser & 87.23 & 1 & 87.23 & 13.70 & .001
\end{tabular}




\section{Hour HR}

With-in Subjects Contrast

\begin{tabular}{lccccc} 
& Sum of Squares & df & Mean Square & F & Sig. \\
\hline Work Shift & 42.96 & 1 & 42.96 & 2.626 & .117 \\
Work Shift * Group & 212.9 & 1 & 212.9 & 13.01 & .001 \\
Total & 425.5 & 26 & & &
\end{tabular}

\section{Hour HR}

\section{Within-Subjects Effects}

\begin{tabular}{|c|c|c|c|c|c|c|}
\hline Source & & $\begin{array}{c}\text { Type III Sum of } \\
\text { Squares }\end{array}$ & df & $\begin{array}{c}\text { Mean } \\
\text { Square }\end{array}$ & $\mathbf{F}$ & Sig. \\
\hline \multirow[t]{2}{*}{ Time } & Sphericity Assumed & 42.96 & 1 & 42.96 & 2.626 & .117 \\
\hline & Greenhouse- Geisser & 42.96 & 1 & 42.96 & 2.626 & .117 \\
\hline Time * & Sphericity Assumed & 212.9 & 1 & 219.9 & 13.01 & .001 \\
\hline Group & Greenhouse-Geisser & 219.9 & 1 & 212.9 & 13.01 & .001 \\
\hline
\end{tabular}


APPENDIX B-1: Updated Repeated Measures ANOVA (24 subjects)

REPEATED MEASURES ANOVA

24 Hour SAP

Within-Subjects Contrast

\begin{tabular}{lccccc} 
& Sum of Squares & df & Mean Square & F & Sig. \\
\hline Work Shift & 36.75 & 1 & 36.75 & 2.494 & .129 \\
Work Shift * Group & 80.08 & 1 & 97.719 & 7.351 & .029 \\
Total & 324.17 & 22 & & &
\end{tabular}

24 Hour SAP

Within-Subjects Effects

\begin{tabular}{|c|c|c|c|c|c|c|}
\hline Source & & $\begin{array}{c}\text { Type III Sum of } \\
\text { Squares }\end{array}$ & df & $\begin{array}{l}\text { Mean } \\
\text { Square }\end{array}$ & $\mathbf{F}$ & Sig. \\
\hline \multirow[t]{2}{*}{ Time } & Sphericity Assumed & 36.75 & 1 & 28.00 & 2.107 & .129 \\
\hline & Greenhouse- Geisser & 36.75 & 1 & 28.00 & 2.107 & .129 \\
\hline Time * & Sphericity Assumed & 80.08 & 1 & 97.71 & 7.351 & .029 \\
\hline Group & Greenhouse-Geisser & 80.08 & 1 & 97.71 & 7.351 & .029 \\
\hline
\end{tabular}




\section{Hour DAP}

\section{With-in Subjects Contrast}

\begin{tabular}{lccccc} 
& Sum of Squares & df & Mean Square & F & Sig. \\
\hline Work Shift & 60.75 & 1 & 60.75 & 10.61 & .004 \\
Work Shift * Group & 65.33 & 1 & 65.33 & 11.415 & .003 \\
Total & 125.91 & 22 & & &
\end{tabular}

\section{Hour DAP}

Within-Subjects Effects

\begin{tabular}{llccccc} 
Source & & $\begin{array}{c}\text { Type III Sum of } \\
\text { Squares }\end{array}$ & df & Square & F & Sig. \\
\hline Time & Sphericity Assumed & 60.75 & 1 & 60.75 & 10.61 & .004 \\
& Greenhouse- Geisser & 60.75 & 1 & 60.75 & 10.61 & .004 \\
Time * & Sphericity Assumed & 65.33 & 1 & 75.33 & 10.61 & .003 \\
Group & Greenhouse-Geisser & 65.33 & 1 & 75.33 & 10.61 & .003
\end{tabular}




\section{Hour MAP}

$\underline{\text { With-in Subjects Contrast }}$

\begin{tabular}{lccccc} 
& Sum of Squares & df & Mean Square & F & Sig. \\
\hline Work Shift & 54.19 & 1 & 54.19 & 7.501 & .012 \\
Work Shift * Group & 77.52 & 1 & 77.52 & 10.74 & .003 \\
Total & 158.8 & 22 & & &
\end{tabular}

\section{Hour MAP}

\section{Within-Subjects Effects}

\begin{tabular}{|c|c|c|c|c|c|c|}
\hline Source & & $\begin{array}{c}\text { Type III Sum of } \\
\text { Squares }\end{array}$ & df & $\begin{array}{c}\text { Mean } \\
\text { Square }\end{array}$ & $\mathbf{F}$ & Sig. \\
\hline \multirow[t]{2}{*}{ Time } & Sphericity Assumed & 54.19 & 1 & 54.18 & 7.507 & .012 \\
\hline & Greenhouse- Geisser & 54.19 & 1 & 54.18 & 7.507 & .012 \\
\hline Time * & Sphericity Assumed & 77.52 & 1 & 77.52 & 10.74 & .003 \\
\hline Group & Greenhouse-Geisser & 77.52 & 1 & 77.52 & 10.74 & .003 \\
\hline
\end{tabular}




\section{Hour HR}

\section{With-in Subjects Contrast}

\begin{tabular}{lccccc} 
& Sum of Squares & df & Mean Square & F & Sig. \\
\hline Work Shift & 16.33 & 1 & 16.33 & 1.103 & .305 \\
Work Shift * Group & 126.75 & 1 & 16.33 & 8.556 & .008 \\
Total & 325.92 & 22 & & &
\end{tabular}

\section{Hour HR}

\section{Within-Subjects Effects}

\begin{tabular}{llccccc} 
& & Type III Sum of & & Mean & & \\
Source & Squares & df & Square & F & Sig. \\
\hline Time & Sphericity Assumed & 16.33 & 1 & 16.33 & 1.103 & .117 \\
& Greenhouse- Geisser & 16.33 & 1 & 16.33 & 1.103 & .117 \\
Time * & Sphericity Assumed & 126.75 & 1 & 126.75 & 8.56 & .001 \\
Group & Greenhouse-Geisser & 126.75 & 1 & 126.75 & 8.56 & .001
\end{tabular}


Total Sleep Work Day vs. Off Day

$\underline{\text { With-in Subjects Contrast }}$

\begin{tabular}{lccccc} 
& Sum of Squares & df & Mean Square & F & Sig. \\
\hline Work Shift & 103200 & 1 & 103200 & 19.38 & .000 \\
Work Shift * Group & 235114 & 1 & 235114 & 44.15 & .000 \\
Total & & 22 & & &
\end{tabular}

Total Sleep Work Day vs. Off Day

$\underline{\text { Within-Subjects Effects }}$

\begin{tabular}{ccccc}
$\begin{array}{c}\text { Type III Sum of } \\
\text { Squares }\end{array}$ & df & $\begin{array}{c}\text { Mean } \\
\text { Square }\end{array}$ & F & Sig. \\
\hline 103200 & 1 & 103200 & 19.38 & .000 \\
10300 & 1 & 103200 & 19.38 & .000 \\
235114 & 1 & 235114 & 44.15 & .000 \\
235114 & 1 & 235114 & 44.15 & .000
\end{tabular}


Raw STAI Anxiety Scores Work Day vs. Off Day

$\underline{\text { With-in Subjects Contrast }}$

\begin{tabular}{lccccc} 
& Sum of Squares & df & Mean Square & F & Sig. \\
\hline Work Shift & 1.408 & 1 & 1.408 & .067 & .798 \\
Work Shift * Group & 29.37 & 1 & 29.37 & 1.397 & .248 \\
Total & & 22 & & &
\end{tabular}

Raw STAI Anxiety Scores Work Day vs. Off Day

Within-Subjects Effects

\begin{tabular}{|c|c|c|c|c|c|c|}
\hline Source & & $\begin{array}{c}\text { Type III Sum of } \\
\text { Squares }\end{array}$ & df & $\begin{array}{l}\text { Mean } \\
\text { Square }\end{array}$ & $\mathbf{F}$ & Sig. \\
\hline \multirow[t]{2}{*}{ Time } & Sphericity Assumed & 1.408 & 1 & 1.408 & .067 & .798 \\
\hline & Greenhouse- Geisser & 1.408 & 1 & 1.408 & .067 & .798 \\
\hline Time * & Sphericity Assumed & 29.37 & 1 & 29.37 & 1.397 & .248 \\
\hline Group & Greenhouse-Geisser & 29.37 & 1 & 29.37 & 1.397 & .248 \\
\hline
\end{tabular}


APPENDIX B-2: Pearson Correlations

PEARSON'S CORRELATIONS

\begin{tabular}{lccc} 
& $\mathbf{n}$ & $\mathbf{r}$ & Sig. (2-tailed) \\
\hline SAP & 28 & -.527 & .004 \\
DAP & 28 & -.622 & .000 \\
MAP & 28 & -.610 & .001 \\
HR & 28 & -.345 & .065
\end{tabular}

SAP, systolic arteriole pressure $(\mathrm{mmHg})$; DAP, diastolic arteriole pressure (mmHg); MAP, mean arteriole pressure ( $\mathrm{mmHg}$ ); HR, heart rate (beats per minute).

\section{MODIFIED PEARSON'S CORRELATIONS}

\begin{tabular}{lccc} 
& n & r & Sig. (2-tailed) \\
\hline SAP & 24 & -.433 & .006 \\
DAP & 24 & -.561 & .001 \\
MAP & 24 & -.571 & .001 \\
HR & 24 & -.270 & .065
\end{tabular}

SAP, systolic arteriole pressure $(\mathrm{mmHg})$; DAP, diastolic arteriole pressure (mmHg); MAP, mean arteriole pressure ( $\mathrm{mmHg}$ ); HR, heart rate (beats per minute). 
APPENDIX B-3: Modified Post Hoc Analysis: Dependent Paired T-Test (24 subject)

MODIFIED POST-HOC ANALYSIS: PAIRED T-TESTS

24 Hour SAP

$95 \%$ Confidence Interval

\begin{tabular}{|c|c|c|c|c|}
\hline & Mean & $\mathbf{N}$ & df & Sig. (2-tailed) \\
\hline $\begin{array}{l}\text { NS Group } \\
\text { Off }\end{array}$ & 120.75 & 12 & 11 & .01 \\
\hline $\begin{array}{c}\text { NS Group } \\
\text { On }\end{array}$ & 125.08 & 12 & 11 & .01 \\
\hline $\begin{array}{l}\text { DS Group } \\
\text { Off }\end{array}$ & 125.42 & 12 & 11 & .637 \\
\hline $\begin{array}{c}\text { DS Group } \\
\text { On }\end{array}$ & 124.58 & 12 & 11 & .637 \\
\hline
\end{tabular}

24 Hour DAP

95\% Confidence Interval

$\begin{array}{ccccc}\begin{array}{c}\text { Mean } \\ \text { Group }\end{array} & 74.67 & 12 & \text { df } & \text { Sig. (2-tailed) } \\ \begin{array}{c}\text { Off } \\ \text { NS Group }\end{array} & 79.25 & 12 & 11 & .001 \\ \begin{array}{l}\text { On } \\ \text { DS Group }\end{array} & 77.08 & 12 & 11 & .001 \\ \begin{array}{l}\text { Off } \\ \text { DS Group }\end{array} & 77 & 12 & 11 & .933 \\ \quad \text { On } & & & & .933\end{array}$

24 Hour MAP $\quad 95 \%$ Confidence Interval

\begin{tabular}{|c|c|c|c|c|}
\hline & Mean & $\mathbf{N}$ & df & Sig. (2-tailed) \\
\hline $\begin{array}{l}\text { NS Group } \\
\text { Off }\end{array}$ & 89.41 & 12 & 11 & .001 \\
\hline $\begin{array}{c}\text { NS Group } \\
\text { On }\end{array}$ & 94.08 & 12 & 11 & .001 \\
\hline $\begin{array}{c}\text { DS Group } \\
\text { Off }\end{array}$ & 92.75 & 12 & 11 & .71 \\
\hline $\begin{array}{l}\text { DS Group } \\
\text { On }\end{array}$ & 92.33 & 12 & 11 & .71 \\
\hline
\end{tabular}




\begin{tabular}{|c|c|c|c|c|}
\hline & Mean & $\mathbf{N}$ & df & Sig. (2-tailed) \\
\hline $\begin{array}{c}\text { NS Group } \\
\text { Off }\end{array}$ & 72.92 & 12 & 11 & .027 \\
\hline $\begin{array}{c}\text { NS Group } \\
\text { On }\end{array}$ & 77.92 & 12 & 11 & .027 \\
\hline $\begin{array}{l}\text { DS Group } \\
\text { Off }\end{array}$ & 72.5 & 12 & 11 & .19 \\
\hline $\begin{array}{c}\text { DS Group } \\
\text { On }\end{array}$ & 70.41 & 12 & 11 & .19 \\
\hline
\end{tabular}

Work Day Sleep vs. Off Day Sleep $\quad 95 \%$ Confidence Interval

$\begin{array}{lcccc} & \text { Mean } & \text { N } & \text { df } & \text { Sig. (2-tailed) } \\ \text { NS Group } & 225.83 & 12 & 11 & .000 \\ \text { DS Group } & -30.0 & 12 & 11 & .359\end{array}$


Original POST-HOC ANALYSIS: PAIRED T-TESTS (28 subjects)

95\% Confidence Interval

24 Hour SAP

\begin{tabular}{lcccccc} 
& Mean & Lower & Upper & t & df & Sig. (2-tailed) \\
\hline NS Group & -4.067 & -6.529 & -1.603 & -3.541 & 14 & .003 \\
DS Group & 1.23 & -2.319 & 4.782 & .755 & 12 & .465
\end{tabular}

24 Hour DAP

\begin{tabular}{lcccccc} 
& Mean & Lower & Upper & t & df & Sig. (2-tailed) \\
\hline NS Group & 4.533 & 2.834 & 6.232 & 5.724 & 14 & .000 \\
DS Group & -.2307 & -2.206 & 1.745 & -.254 & 12 & .803
\end{tabular}

24 Hour MAP

\begin{tabular}{lcccccc} 
& Mean & Lower & Upper & t & df & Sig. (2-tailed) \\
\hline NS Group & 4.466 & 2.527 & 6.406 & 4.93 & 14 & .000 \\
DS Group & -.5384 & -2.739 & 1.662 & -.533 & 12 & .604
\end{tabular}

24 Hour HR

\begin{tabular}{lcccccc} 
& Mean & Lower & Upper & t & df & Sig. (2-tailed) \\
\hline NS Group & 5.666 & 2.172 & 9.160 & 3.478 & 14 & .004 \\
DS Group & -2.153 & -5.143 & .8356 & -1.750 & 12 & .142
\end{tabular}

Work Day Sleep vs. Off Day Sleep (total sleep minutes) $\quad 95 \%$ Confidence Interval

\begin{tabular}{lcccccc} 
& Mean & Lower & Upper & t & df & Sig. (2-tailed) \\
\hline NS Group & -206.6 & -258.5 & -154.7 & -8.543 & 14 & .000 \\
DS Group & 37.69 & -27.34 & 102.7 & 1.263 & 12 & .231
\end{tabular}


POST-HOC ANALYSIS: PAIRED T-TESTS

24 Hour SAP

$\begin{array}{ccccc}\text { NS Group } & 120.75 & 12 & \text { df } & \text { Sig. (2-tailed) } \\ \begin{array}{c}\text { Off } \\ \text { NS Group }\end{array} & 125.08 & 12 & 11 & .01 \\ \begin{array}{l}\text { On } \\ \text { DS Group }\end{array} & 125.42 & 12 & 11 & .01 \\ \quad \begin{array}{l}\text { Off } \\ \text { DS Group } \\ \quad\end{array} & 124.58 & 12 & 11 & .637 \\ \text { On } & & & & .637\end{array}$

24 Hour DAP

95\% Confidence Interval

\begin{tabular}{|c|c|c|c|c|}
\hline & Mean & $\mathbf{N}$ & df & Sig. (2-tailed) \\
\hline $\begin{array}{c}\text { NS Group } \\
\text { Off }\end{array}$ & 74.67 & 12 & 11 & .001 \\
\hline $\begin{array}{l}\text { NS Group } \\
\text { On }\end{array}$ & 79.25 & 12 & 11 & .001 \\
\hline $\begin{array}{l}\text { DS Group } \\
\text { Off }\end{array}$ & 77.08 & 12 & 11 & .933 \\
\hline $\begin{array}{c}\text { DS Group } \\
\text { On }\end{array}$ & 77 & 12 & 11 & .933 \\
\hline
\end{tabular}

24 Hour MAP $\quad 95 \%$ Confidence Interval

\begin{tabular}{|c|c|c|c|c|}
\hline & Mean & $\mathbf{N}$ & df & Sig. (2-tailed) \\
\hline $\begin{array}{c}\text { NS Group } \\
\text { Off }\end{array}$ & 89.41 & 12 & 11 & .001 \\
\hline $\begin{array}{l}\text { NS Group } \\
\text { On }\end{array}$ & 94.08 & 12 & 11 & .001 \\
\hline $\begin{array}{l}\text { DS Group } \\
\text { Off }\end{array}$ & 92.75 & 12 & 11 & .71 \\
\hline $\begin{array}{l}\text { DS Group } \\
\text { On }\end{array}$ & 92.33 & 12 & 11 & .71 \\
\hline
\end{tabular}


APPENDIX C: Subject Information Questionnaire

Name:

Date:

Height:

Weight:

Age:

Gender: $\mathrm{M} \quad \mathrm{F}$

Resting BP: 1)

2)

3)

Questions:

Do you smoke?

Yes No

Do you have asthma?

Yes No

Have you ever fainted?

Yes No

Have you ever had a stroke or heart attack?

Did you consume caffeine in the last 12 hours?

Have you consumed alcohol in the last 12 hours?

Do you take heart/blood pressure medication?

Are you taking any other medications?

Yes No

Yes No

Yes No

Yes No

Yes No

If yes, please list:

How many years and/or months have you been a nurse?

How many years and/or months have you had your current 12 hour shift schedule?

Females Only:

Number of days since the start of your last menstruation:

Are you pregnant or breastfeeding? $\quad$ Yes No

Are you taking oral contraceptives? $\quad$ Yes No

If yes, what type:

$\begin{array}{lll}\text { Is your menstrual cycle regular? } & \text { Yes } & \text { No }\end{array}$

Typical number of days a cycle lasts: 
APPENDIX D: STAI Questionnaire, Form Y-1

(C) 1968, 1977 Charles D. Spielberger. All Rights Reserved.

\section{SELF-EVALUATION QUESTIONNAIRE STAI Form Y-1 \\ Please provide the following information:}

Name

Age Gender (Circle) M F T

Date

1. I feel calm

2. I feel secure

3. I am tense

4. I feel strained

5. I feel at ease

\section{DIRECTIONS:}

A number of statements which people have used to describe themselves are given below. Read each statement and then circle the appropriate number to the right of the statement to indicate how you feel right now, that is, at this moment. There are no right or wrong answers. Do not spend too much time on any one statement but give the answer which seems to describe your present feelings best.

$1-$ Not at all

2 - Somewhat

3 - Moderately so

4 - Very much so 
APPENDIX D-1: STAI Questionnaire, Form Y-2

(C) 1968, 1977 Charles D. Spielberger. All Rights Reserved.

\section{SELF-EVALUATION QUESTIONNAIRE STAI Form Y-2}

Name

Date

21. I feel pleasant

1234

22. I feel nervous and restless

1234

23. I feel satisfied with myself.

1234

24. I wish I could be as happy as others seem to be

1234

25. I feel like a failure

1234

DIRECTIONS:

A number of statements which people have used to describe themselves are given below. Read each statement and then circle the appropriate number to the right of the statement to indicate how you generally feel. (C) 1968, 1977 Charles D. Spielberger. All Rights Reserved.

$1-$ Not at all

2 - Somewhat

3 - Moderately so

4 - Very much so 


\section{APPENDIX D-2: STAI Approval Letter}

To Jennifer L. Witting,

This letter is to grant permission for the above named person to use the following Copyright material:

Instrument: State-Trait Anxiety Inventory for Adults

Authors: Charles D. Spielberger, in collaboration with R.L. Gorsuch, G.A. Jacobs, R. Lushene, and P.R. Vagg

Copyright: 1968, 1977 by Charles D. Spielberger

for his/her thesis research.

Five sample items from this instrument may be reproduced for inclusion in a proposal, thesis, or dissertation.

The entire instrument may not be included or reproduced at any time in any other published material.

Sincerely, Robert Most

Forwarded by: Valorie Keller, Mind Garden, Inc.

http://mindgarden.com

Date: August 2, 2011 
APPENDIX E: Caffeine Intake Report Sheet

Name:

Height:

Weight:

Age:

Gender: M

$\mathrm{F}$

$\underline{\text { Caffeine intake during shift: please list approximate time and how much }}$

Time:

Time:

Time:

Time:

Time:

Time:

Time:
Amount

Amount:

Amount

Amount

Amount

Amount

Amount

Date 


\section{APPENDIX F: Self Report Sleep Diary}

Name:

Date:

Time went to bed test one:

Time awoke test one:

Quality of sleep:

Time went to bed test two:

Time awoke test two:

Quality of sleep: 
APPENDIX G: Recruitment Flyer

$$
\text { **RECRUITING** }
$$

Subjects for a 24 Hour

Ambulatory Blood Pressure Study

A study approved by the Michigan Tech Institutional Review Board is underway in the Exercise Science, Health \& Physical Education Department. YOU CAN HELP CONTRIBUTE TO FURTHER UNDERSTANDING OF THE EFFECTS OF NIGHT SHIFT WORK ON THE HUMAN BODY.

We are looking to recruit male and female staffs, who currently work 12 hour night shift or 12 hour day shifts to be part of two step study on the effects of night shift work on the human body.

This is a voluntary study (i.e., no compensation).

\section{Study Restrictions:}
* Non-Smoker
* Non-Diabetic
* Cannot be taking heart/BP medications
* Cannot be pregnant

For more information about this study, please contact:

- Jennifer Witting, Masters Student jlwittin@mtu.edu

- Jason Carter, Dept. Chair - ESHPE jcarter@mtu.edu

- Or contact the ESHPE office: (906) 487-2715 